\title{
La gente de Ovando en los protocolos hispalenses
}

\section{Juan Gil}

Universidad de Sevilla

Se reúne y sistematiza en este artículo toda la documentación referente a la armada de Ovando contenida en los protocolos de Sevilla.

Palabras Clave: Ovando, Santo Domingo, Española, armadas a Indias.

In this paper are collected and organised all the documents relating to the Ovando's fleet found in the Notarial Archive of Seville.

KeY-words: Ovando, Santo Domingo, Española, fleets to the Indies.

En vida de Cristóbal Colón se produjeron tres grandes movimientos migratorios a las Indias: en 1493, en 1502 y en 1506. Me propongo estudiar los dos últimos, los menos conocidos, en sendos artículos, ya que me parece útil presentar organizado un material desconocido o disperso hasta ahora en los muy valiosos volúmenes publicados por la Fundación Rafael G. Abreu.

El 13 de febrero de 1502 partió de Sanlúcar de Barrameda la gran armada - treinta y dos naves — de fray Nicolás de Ovando, de la que fue por capitán general Antonio de Torres. Traspapelado el legajo que correspondía al despacho de la misma en el Archivo de Indias (signatura antigua 32-3-2/21), el Archivo de Protocolos es hoy por hoy la fuente principal para estudiar la composición de la gente que fue en aquella expedición. Desgraciadamente, la serie de legajos correspondientes a los años 1501 y 1502 está muy incompleta, de suerte que sólo sirven para nuestro propósito los seis siguientes, correspondientes a cinco oficios:

$\begin{array}{clcr}\text { Oficio } & \text { III 1501 (= 1499) } & \text { citado como } & 3.1501 \\ \text { “ } & \text { IV 1501,2(=2160) } & \text { “ } & 4.1501 \\ \text { “ } & \text { V 1501 }=3221) & \text { “ } & 5.1501 \\ \text { “ } & \text { IX 1501 (=17427) } & \text { “ } & 9.1501 \\ \text { “ } & \text { XV 1501 (=9101) } & \text { “ } & 15.1501 \\ \text { “ } & \text { IV 1502 (=2161) } & \text { “ } & 4.1502\end{array}$


Aun así, y a pesar de su estado tan fragmentario, las escribanías hispalenses nos dan a conocer los nombres de 298 pasajeros (incluidos los dudosos), una porción verdaderamente considerable, aunque mínima, de lo que fue la expedición. En efecto, según Las Casas, "la gente que se embarcó llegaron a dos mil y quinientos hombres; muchos entre ellos, y los más, eran personas nobles, caballeros y principales". Es probable que así sucediera de verdad, aunque no cabe descartar que el dominico añadiese algo de su fantasía para colorear su propia experiencia vital con más noblezas y caballerías de las existentes. Sea como fuere, en cualquier caso los protocolos nos presentan la otra cara de la moneda, el aspecto más sórdido: por desgracia, también el más ajustado a la realidad. Mayoritariamente los hombres que aparecen por sus registros no son ni mucho menos gente de postín, sino pobres asalariados que contratan sus servicios por varios años, buscando en las Indias el medro que les niega su tierra de nacimiento. Por lo general la edad de estos trabajadores, cuando la conocemos, no suele sobrepasar los treinta años: fían a un albur la flor de la vida. No hay ninguna mujer, aunque pasaron algunas, con o sin marido.

Las escrituras abarcan una amplia horquilla temporal: la primera se firma muy tempranamente, el 18 de agosto de 1501, mientras que la última conocida data del 18 de enero de 1502; su flujo — nada sorprendentemente- aumenta progresivamente y se dispara en los meses de octubre, noviembre y diciembre. Los oficios de las personas que se disponen a ir al Nuevo Mundo son muy diversos:

aserradores: $2(1,87)$.

barberos: $3(14,190,192)$.

ballesteros: 1 (23).

boneteros: 1 (134).

carpinteros: 1 (20).

correeros: 1 (295).

curtidores: $2(2,271)$.

escribanos: $2(7,35)$.

escuderos: $(48,94,151,186,207,238,246)$.

físico: 1 (96).

freneros: 1 (26).

fruteros: 1 (125).

herreros: 3 (¿59?, 99, 207).

lavadores de oro: $4(5,8,85,244)$. merchantes de bestias: 1 (296).

orilleros: 1 (55).

pintores de imaginería: 1 (90).

plateros: $2(40,145)$.

sastre: $(30,89,185)$.

silleros: 1 (285).

tejedores: 3 (126, 142, 219).

toqueros: 1 (60).

tundidores: 1 (135).

trabajadores: $36(3,9,15,16,21,36,54,57$, $61,62,66,75,83,86,93,111,116,127$, $132,144,158,197,200,201,210,219$, $229,231,258,260,270,273,274,275$, 277, 294).

1 Las Casas, B.: Historia de las Indias, Edic. J. Pérez de Tudela, Madrid, Atlas, 1957, vol. II, pág. 12. 
Forman el grueso de la gente las personas desheredadas de la fortuna que carecen de oficio y sólo pueden ofrecer sus brazos. Siguen en número los escuderos, cosa nada de extrañar, pues las Indias precisan de hombres de armas: a su llegada la armada se encontrará con un alzamiento de los indios de Higüey. Pero a continuación vienen los lavadores de oro, señal de que el metal dorado había hecho finalmente su gozosa aparición, haciendo realidad el sueño visionario tenido por Colón en 1499: poco antes de la arribada se había encontrado una pepita de valor incalculable. La misma alegría quizás puede justificar la presencia de dos plateros, necesarios en la fundición del oro. Los tres barberos harían las veces de sangradores y cirujanos, aunque un físico a sueldo de los reyes, Diego Ponce, está decidido a suplir la prolongada ausencia de Diego Álvarez Chanca. Llama la atención que acuda ya a las Indias un pintor de imaginería, como si empezara a prometer el mercado de arte sacra; la sorpresa es que su sueldo no sea muy superior al de los simples trabajadores. Pasan asimismo dos escribanos, uno de ellos nombrado por el rey: el asentamiento primitivo comienza a civilizarse. A que Santo Domingo tenga una pátina más castellana contribuye la presencia de boneteros, toqueros, sastres y todos cuantos se dedican a confeccionar prendas de vestir: un bonetero, Francisco Jiménez (134), pretende montar un emporio comercial en Santo Domingo, tanto con el desempeño de su oficio como dedicándose a otras actividades, como lavar oro. Imprescindibles son los herreros; de los no menos precisos carpinteros sólo aparece uno.

El estamento eclesiástico está representado por tres clérigos, Alonso Fernández, Alonso Guiral y Esteban de Molina $(11,17,101)$, y el presbítero Martín Martínez (249), no mencionados curiosamente por Las Casas, su compañero de viaje. En cambio, es lógico que los doce franciscanos brillen por su ausencia: el voto de pobreza impide a la Orden utilizar los servicios de los escribanos salvo en casos excepcionales.

Otros pasajeros, más afortunados, hacen su agosto con la expedición. Son los contratantes: Carlos de Hontiveros (69), Diego de Nicuesa (94), el futuro capitán que arrastra consigo a no pocos hombres de Torredonjimeno, su villa natal, el cacereño Gonzalo de Ocampo (165), el mercader sevillano Fernando de León (112), el sanluqueño Fernando de Lugo (114), Francisco de Pomareda (141), el bonetero Francisco Jiménez (134), Frutos de Deleitosa (154), Gómez de Alfaro (160), Juan de Mojados (205), hijo de Pedro de Medina (notario de la Inquisición sevillana), un avispado mozo dotado de espíritu emprendedor, y Juan de Molina (206). Por su parte, 
Pedro de Salzedo (278), el fiel maestresala de Colón, y Luis de Arriaga (238) se enriquecen vendiendo vino a los expedicionarios. A esta burguesía más acomodada pertenecen asimismo el médico y los eclesiásticos.

Otros prohombres de las Indias, como los baquianos Diego Marque (91), Diego de Escobar (84), Martín de Gamboa (247) o el jerezano Gil Delgado (157; sin duda el Gil Delgadillo del tercer viaje), pasan esta vez más de puntillas por las escribanías sevillanas; lo mismo cabe decir de Francisco de Piédrola (140), que será más tarde capitán de una nave, de Álvaro Bravo (39) o de Rodrigo de Alburquerque (283), el futuro repartidor de indios. De familias más o menos encopetadas de Sevilla descienden Alonso Manuel de Lando (22), Fernando Ponce de León (118), hijo de D. Alfonso Ponce de León, Juan Barba (179) y Juan de Esquivel (189), quien habría de fundar en Jamaica la efímera ciudad de Nueva Sevilla.

Un caso curioso es el de Cristóbal de Palacios, un hombre de color loro que parece ser un esclavo ahorrado (76), si bien tiene dinero suficiente para contratar a su vez a otro mestizo o esclavo. El único negro, al parecer, es Pedro (255), un antiguo criado del mercader genovés Jácome de Sorvanis, mas tampoco se especifica si está manumitido o no.

Los grandes señores meten baza en Indias por medio de sus paniaguados. Es notable que sólo aparezcan dos hombres del rey: Diego (81) y quizá Lozano (297). Don Enrique Enríquez, tío de Fernando el Católico y su mayordomo mayor, envía a sus criados Diego de Nicuesa (94)² y Martín de Gamboa (246). El arzobispo de Mesina (don Pedro de Belorado), antiguo inquisidor de Sevilla, está representado por el loro Cristóbal de Palacios (76), de quien acabamos de hacer mención. Pedro Fajardo, el adelantado de Murcia, se sirve de Juan de Ortuvia (211). La condesa de Camiña manda a Luis Monte (242). A menor escala, fray Nicolás de Ovando procura rodearse de fieles, haciéndose acompañar por hombres de su confianza: aquí figuran Álvaro Bravo (39) y Andrés de Gramiña (48).

Los comerciantes sevillanos sacan asimismo tajada del despacho de la armada. Unos prestan dinero a los expedicionarios o a los maestres: así Juan Pérez —quizá Juan Pérez Cisbón (86, 200), Alonso de Perona (34), Ruy González de la Sal (maestres, 5), Luis Guerra (maestres, 5), Juan Bastidas (maestres, 13) y Tomás de Palenzuela (206)—. Otros —lo más común - venden fiados productos o vituallas: el mismo Tomás de Palenzuela (13) aceite, Pedro Rodríguez (187) vino, el herrero Juan de

2 Fue su "trinchante", al decir de Las Casas. Ibídem, pág. 127. 
Monleón (180) herramientas, Alonso de Perona (206), Juan Sánchez de la Tesorería (94), Gonzalo Rodríguez (98), el barbero Juan García (199) y el curtidor Pedro Arias (219) mercancías diversas, Juan de la Palma (71), vecino de Sevilla, ropa y Pedro de Sanlúcar (76) paño. Los beneficios se extienden a los habitantes de la zona onubense: entre los gananciosos se encuentran Álvar Alonso Rascón (238), vecino de Palos, Juan de la Palma, vecino de Trigueros (91), y Alonso Fernández de Bolaños, regidor de Gibraleón (maestres, 1, 8).

Las mercancías que se cargan en las naves atienden por lo general a las necesidades personales de cada pasajero: así ocurre con el vino que vendieron al por menor Luis de Arriaga y Pedro de Salzedo a algunos expedicionarios. No pasan ante los escribanos grandes negocios, aunque Juan Sánchez de la Tesorería, al arrimo de Francisco de Riberol, acechase la oportunidad favorable para emprender un comercio a gran escala. Del envío de animales sólo queda constancia en un caso: los once cerdos que llevaron en sus carabelas Alonso Venegas (maestres, 1) y Francisco García (maestres, 8) y que costaron a $500 \mathrm{mrs}$. la pieza, el precio normal en aquella época; es probable que, en parte, se hubiesen asilvestrado ya para entonces los puercos que habían tratado de aclimatar a las Indias los pobladores de la Isabela.

Esta nueva ola de emigrantes procede de todas las regiones de España. Muchos vienen de Extremadura, Andalucía o las dos Castillas, pero también de Galicia (7, 37, 191, quizá 27), Asturias (20, 28, 106, 177, 256, 259), La Montaña $(244,254)$ y las Provincias Vascongadas (53). A pesar de la expresa afirmación en contra de Gonzalo Fernández de Ovie$\mathrm{do}^{3}$, tampoco faltan catalanes (186), aragoneses (23), valencianos (214, 291) y hasta mallorquines (54). Cuatro son portugueses $(42,88,164$, 201), que se añaden por lo menos a los otros cuatro a quienes los reyes dieron licencia para ir a poblar a la Española el 17 de enero de $1502^{4}$; hay un gascón (87) y, por fin, otro parece ser un flamenco oriundo de Bruselas (263).

Pocas palabras bastarán para explicar la disposición del material inventariado. El rol está organizado por orden alfabético de nombres propios. Para facilitar la búsqueda, he agrupado los dobletes (Antón/Antonio,

3 Ibídem, pág. 69: "en tanto que la católica reina doña Isabel vivió, no se admitían ni dejaban pasar a las Indias sino a los proprios súbditos... e no aragoneses, ni catalanes, ni valencianos".

4 Real Academia de la Historia, Colección documental del Descubrimiento. 1470-1506, Madrid, Mapfre, CSIC, 1994, pág. 1411. 
Álvar/Álvaro), pero manteniendo el mismo orden; sólo me he permitido fundir en uno los Alonsos y los Alfonsos. Las cansinas escrituras de prestación de servicios se han abreviado al máximo: tras el nombre del asalariado se indica con quién va, la duración del servicio y el sueldo anual. Cuando el pasajero procede de Sevilla, se señala sólo la colación. En los contratos y en las escrituras hechas por varias personas se da entrada a todos los firmantes dispuestos a pasar a Indias, pero sólo se especifica la referencia documental en la entrada del primero. Las abreviaturas son fácilmente comprensibles: h. (hijo), m. (muerto), n. (natural), v. (vecino). Utilizo las siguientes siglas:

BC (B. de las Casas, Historia de las Indias).

CDD (Real Academia de la Historia, Colección documental del Descubrimiento. 1470-1506, Madrid, 1994).

G-F (M. Giménez Fernández, Bartolomé de las Casas, II, Sevilla, 1960.

GFO (Gonzalo Fernández de Oviedo, Historia general y natural de las Indias).

Gil Conv. (J. Gil, Los conversos y la Inquisición sevillana, Sevilla, 2000ss.).

Gil MyM (J. Gil, "Marinos y mercaderes en Indias (1499-1504"), An. Est. Am., XLII (1985) 297-288).

HC (Le Historie della vita e dei fatti di Cristoforo Colombo per D. Fernando Colombo suo figlio, ed. R. Caddeo, Milán, 1930).

R-D (E. Rodríguez Demorizi, Los dominicos y las encomiendas de indios de la isla Española, Santo Domingo, 1971).

\section{PASAJEROS}

1. Alonso aserrador, n. de Aracena. 12-1-02: con Amador de Cabrera (Santa María). 2 años. A medias, sacadas las costas (4.1502, f. 71v). 24-1-02: hizo su personero a Alonso Domínguez, n. de Aracena, dándole poder general $(4.1502$, f. $129 \mathrm{v})$.

2. Alonso de Alba, curtidor. 17-11-01: los curtidores Álvaro Ruiz, Pedro de Madrid, Diego de Madrid y Alonso de Alba deben a Juan Sánchez de la Tesorería (Santa María), 8.000 mrs. de mercadería despachada en la carabela Santa Ana (maestre: Juan Asejo, v. de Palos), en la que se disponían a ir a las Indias Alonso de Alba y Pedro de Madrid: a pagar en Santo Domingo (5.1501, f. 209r). 


\section{LA GENTE DE OVANDO EN LOS PROTOCOLOS HISPALENSES}

3. Alonso de Antequera, trabajador, n. de Antequera. 12-1-02: con Amador de Cabrera (Santa María). 2 años. A medias, sacadas las costas (4.1502, f. 71v).

4. Alonso de Argüello (escrito "Arguelo"), v. de Castromocho. 20-9-01: con el tejedor Francisco de Rojas (San Lorenzo). 2 años. 8.000 mrs. (4.1501, f. 202r). Se avecindó en Lares de Guahaba (R-D 210).

5. Alonso de Carrión, lavador de oro (Santa María). 15-10-01: con el bonetero Francisco Jiménez (Santa María). 15 meses. 5/8 partes de las ganancias (3.1501, f. 808v). El mismo día Jiménez le dio 1.875 mrs. de préstamo: a pagar en la Española en un plazo de dos meses y, si no fuere en ese viaje, en Sevilla en la Navidad siguiente (3.1501, f. 808v).

6. Alonso de Castro, v. de Jaén. 22-11-01: junto con Frutos de Deleitosa y Juan de Ortuvia debe a Juan de Mojados $16.575 \mathrm{mrs}$. por mercaderías que le habían comprado (3.1501, f. 922r).

7. Alonso Díaz, escribano, h. de Alonso Díaz de Cadórniga, v. de Orense. 21-10-01: con Álvar García de Medellín (Cestería). 2 años. 7.000 mrs. más el $10 \%(3.1501$, f. $831 \mathrm{v})$.

8. Alonso de ¿Entran?, lavador de oro. 19-10-01: debe al bonetero Francisco Jiménez quince pesos de oro de préstamo: a pagar en la Española en un plazo de veinte días $(3.1501$, f. $819 \mathrm{v})$.

9. Alonso de Escalona (mayor de 19 años), trabajador, h. de Jerónimo Martín, v. de Escalona. 3-11-01: con Carlos de Hontiveros. 3 años. 7.000 mrs. (15.1501, f. 671v).

10. Alonso de Espinosa, v. de Espinosa. 8-11-01: con Martín Martínez, presbítero. 2 años. 6.000 mrs. más el $10 \%$ (15.1501, f. 688r).

11. Alonso Fernández, clérigo de la veintena de Sevilla. 20-10-01: contrata a Alonso González y a Francisco González. Es uno de los cuatro sacerdotes mencionados por CDD III, 1419.

12. Alonso Fernández de Castilla (Omnium sanctorum). 3-1-02: debe a Martín Fernández Pacho (San Andrés), maestre de la carabela San Andrés, 8.000 mrs. que le prestó para comprar mercancías y vituallas, que van a riesgo de Fernández: a pagar en Santo Domingo (4.1502, f. 8v).

13. Alonso Fernández Melgarejo, h. de Pedro de Urrea (San Román). 11-1-02: de mancomún con Juan Barba debe a debe a Tomás de Palenzuela 21.000 mrs. de 18 quintales de aceite para cargar en la nao de Peñafiel.

14. Alonso García, barbero (Santa María). 22-11-01: de mancomún con el barbero Juan García compra mercaderías a Juan Sánchez de la Tesorería por valor de $12.255 \mathrm{mrs}$.

15. Alonso González, trabajador, marido de Leonor González, v. de San Vicente (Valencia de Alcántara). 20-10-01: con Alonso Fernández, clérigo de la veintena de Sevilla. 2 años. 5.000 mrs. más el $10 \%$ (15.1501, f. 616r). 
16. Alonso de Guadalupe (mayor de 20 años y menor de 25), trabajador, h. de Antón Escribano Carrascalejo, n. de Guadalupe. 3-12-01: con Fernando de León (Santa María). 3 años. 6.000 mrs. (5.1501, f. 247r).

17. Alonso Guiral, clérigo (Santa María). Contrata a Juan Caballos (2-11-01), Francisco de ¿Leanca? (13-1-02) y Cristóbal de Peñalar (13-1-02). Es uno de los cuatro sacerdotes mencionados por $C D D$ III, 1419, si bien llamándolo "Fernando". La lectura del documento, muy clara, no deja lugar a dudas. Cf. Fernando Guiral.

18. Alonso Gutiérrez (no parece que sea Alonso Gutiérrez de Villanueva). 25-10-01: contrata a Antón Bravo.

19. Alonso Gutiérrez de Villanueva (Santa María), mayor de 22 años y menor de 25. 25-9-01: de mancomún con Luis Monte y Gómez de Sauzedo debe al mercader Fernando de León (Santa María) 3.000 mrs.: a pagar en la Española a los quince días de su llegada a tierra y, si no fueren en ese viaje, en Sevilla en un plazo de seis meses (3.1501, f. 753r).

20. Alonso de Lago, carpintero, n. de las Asturias de Oviedo. 23-10-01: con el físico Diego Ponce (Magdalena). 3 años. 5.000 mrs. más el $10 \%$ (3.1501, f. $839 v$ ).

21. Alonso López, trabajador, h. de Luis López (m.), v. de Córdoba (Santiago). 11-9-01: con Diego de Ulloa, v. de Zamora. 2 años. 10.000 mrs. (4.1501, f. 126v).

22. Alonso Manuel < de Lando > (mayor de 23 años y menor de 25), h. del difunto Alonso Manuel (Magdalena). 13-12-01: hace una compañía con Juan Manuel de Lando, su primo (San Isidoro), que desde Sevilla lo provee de todo lo necesario, herramientas incluidas. Tiempo indefinido. A medias (5.1501, 1 [= 3220], f. 262v). El mismo día Alonso Manuel hace compañía a medias con el tundidor Francisco Jiménez, v. de Ledesma (mayor de 24 años y menor de 25), para trabajar en las Indias (5.1501, f. 263r).

23. Alonso Martín, ballestero, n. de Tarazona. 9-11-01: con Gómez de Alfaro, v. de Madrid. 3 años. 6.000 mrs. (3.1501, f. 887v).

24. Alonso Martín Riero (¿de Rieros?), v. de Usagre (Orden de Santiago). 19-10-01: con Juan Patiño (Santa María). 2 años. 7.000 mrs. más el $10 \%$ (3.1501, f. 818v).

25. Alonso de Martos (mayor de 22 años y menor de 25), h. de Alonso de Ca*** (m.), n. de Martos. 5-10-01: con Alonso de Oviedo, h. del comendador Alonso de Oviedo (m.), v. de Torredonjimeno. 2 años. 8.000 mrs. (5.1501, f. $175 v)$.

26. Alonso de Mayorga, frenero, h. de Alonso Gutiérrez, n. de Mayorga (lugar del conde de Benavente). 13-12-01: con Juan Quintero Príncipe, v. de Palos. 5 meses. El $10 \%$ del oro (5.1501, f. 262 r).

27. Alonso de Mondoñedo (24 años), h. de Gonzalo de León, v. de León. 4-1101: con Carlos de Hontiveros. 3 años. 10.000 mrs. (15.1501, f. 676r). 


\section{LA GENTE DE OVANDO EN LOS PROTOCOLOS HISPALENSES}

28. Alonso Montañés, n. de la Liébana. 23-9-01: con Juan Alvarez de Gijón (v. de Valladolid). 3 años y aún más, si Juan Álvarez estuviere más tiempo en las Indias. 5.000 mrs. (4.1501, f. 183v). Se avecindó en Santo Domingo (R-D 154).

29. Alonso de ¿Moriana? (Baeza). 9-12-01: contrata a Juan de la Nava.

30. Alonso Núñez (mayor de 23 años y menor de 25), sastre, h. de Pedro Núñez (m.), n. de Acona (Zorita de los Canes). 6-12-01: con el albañil Felipe Rodríguez. Un año. Pide ropa a cambio de su servicio (3.1501, f. 954r).

31. Alonso Núñez de Toledo (Santa Cruz). 23-12-01: contrata a Pedro de Herrera.

32. Alonso de Oviedo, h. del comendador Alonso de Oviedo, v. de Torredonjimeno. 5-10-01: contrata a Alonso de Martos.

33. Alonso de Pallares, v. de Zamora. 9-12-01: compra vino a Luis de Arriaga y a Pedro de Salzedo. Vivía en la Española en 1514 (R-D 94, 98).

34. Alonso de Paredes, v. de La Puebla de Montalbán, borceguinero. 11-11-01: con Fernando de Villada (San Lorenzo) y con Lope Álvarez, v. de Ciudad Real. 2 años. 6.000 mrs. más el $10 \%$ (3.1501, f. 896r).

35. Alonso Rodríguez de Valdés, escribano real (Magdalena). 13-12-01: junto con Diego de Escobar (Omnium sanctorum) debe a Alonso de Perona (San Bartolomé) 4.000 mrs. de mercadería que va cargada en la nao Santo Domingo (maestre: Juan de Peñafiel): a pagar en Sevilla o en Cádiz (5.1501, f. 264r).

36. Alonso Tamariz, trabajador, n. de Tamariz. 19-10-01: con el albañil Francisco de Salas (Omnium sanctorum). 2 años. 7.500 mrs. más el $10 \%$ (3.1501, f. 819r).

37. Alonso Tejeiro, gallego, v. de la Española. 9-12-01: debe a Luis de Arriaga y a Pedro de Salzedo $1.810 \mathrm{mrs}$. de una bota de vino $(15.1501$, f. $769 \mathrm{v})$.

38. Alonso de Toro, n. de Toro, h. de Juan Morán. 20-10-01: con Fernando del Alcázar (Santa Cruz). 1 año. El $25 \%$ (3.1501, f. 827v).

39. Álvaro Bravo, criado del comendador de Lares, fray Nicolás de Ovando (San Isidoro). Contrata a Andrés de ¿Gramiña? (1-10-01), Martín Domínguez (14-10-01) y Pedro Cabelo (10-12-01). Avecindado en Santo Domingo (R-D 139), testificó en 1517 en el juicio de residencia que hizo Zuazo a los jueces de apelación de la Española (AGI Just. 42, f. 262v) y firmó a fines de ese año un memorial dirigido al rey con otros vs. de la ciudad (G-F II, 133).

40. Álvar Díaz, platero (Santa María). Contrata a Juan de Gálvez (7-10-01) y a Fernando de Torres (12-11-01).

41. Álvar García de Medellín (Cestería). 21-10-01: contrata a Alonso Díaz .

42. Álvaro Gonçales, portugués (Santa María). 5-10-01: con el físico Diego Ponce (Salvador). Durante todo el tiempo que el doctor estuviere en la Española. A medias (3.1501, f. 780r). 
43. Alvaro de Jerez, h. de Juan de Jerez, v. que fue de Sevilla. 3-11-01: con Carlos de Hontiveros. 3 años. 10.000 mrs. (15.1501, f. 670v).

44. Álvar Pérez de ¿Incuestes?, v. de Medina del Campo. 9-12-01: debe a Luis de Arriaga y a Pedro de Salzedo 2.320 mrs. de una bota de vino (15.1501, f. 770v).

45. Amador de Cabrera (Santa María). 12-1-02: contrata a Alonso aserrador y a Alonso de Antequera.

46. Andrés Cutiño, v. de Ávila. 18-1-02: contrata a Juan de Espinosa.

47. Andrés García, de color loro, criado que fue de Juan de la Palma, estante en Sevilla. 13-10-01: con Cristóbal de Palacios, de color loro, v. de Trigueros. 4 años. 8.000 mrs. (3.1501, f. 804r).

48. Andrés de ¿Gramiña?, escudero (Santa María), marido de Juana López. 1-10-01: con Álvaro Bravo, criado del comendador de Lares. 2 años. 4.000 mrs. (3.1501, f. 766v).

49. Antón *** (Magdalena). 9-12-01: debe a Luis de Arriaga y a Pedro de Salzedo 1.810 mrs. de una bota de vino (15.1501, f. 769r).

50. Antonio de Aguilar (Santa María). 9-12-01: debe a Luis de Arriaga y a Pedro de Salzedo 3.310 mrs. de una bota de vino (15.1501, f. 771v).

51. Antón Bravo (mayor de 20 años), n. de Cáceres. 25-10-01: con Francisco de Godoy, Alonso Gutiérrez y Rodrigo de Grivalda. 3 años. 4.000 mrs. más el $10 \%$ (15.1501, f. 632v).

52. Antón García de Buitrago. 16-8-01: contrató a Juan de Brizuela. 9-12-01 (llamado aquí sólo García de Buitrago, v. de Aranda de Duero): debe a Luis de Arriaga y a Pedro de Salzedo 3.620 mrs. de dos botas de vino (15.1501, f. 769r).

53. Antón de Horozco, h. de Antón de Horozco, n. de Orozco. 10-11-01: con Carlos de Hontiveros. 3 años. 10.000 mrs. (15.1501, f. 713r).

54. Antón Mallorquín (mayor de 20 años), trabajador, n. de Mallorca. 27-10-01: con Gómez de Alfaro, v. de Madrid. 5 años. 6.000 mrs. (3.1501, f. 856v).

55. Antonio de Salamanca (23 años), orillero. 3-11-01: con Carlos de Hontiveros. 3 años. 10.000 mrs. (15.1501, f. 671r).

56. Antón de Tarifa (mayor de 18 años y menor de 25), h. de Pedro de Tarifa, n. de Cartagena. 7-10-01: con Diego de Nicuesa, criado de don Enrique Enríquez. 2 años. 6.000 mrs. (5.1501, f. 183r).

57. Antón Vázquez, trabajador, marido de Aldonza Rodríguez (San Marcos). 30-9-01: con el albañil Francisco de Salas (Omnium sanctorum). 2 años. 9.000 mrs. (3.1501, f. 764v).

58. Atanasio Pedro Díaz de la Costana (Azuaga, maestrazgo de Santiago). Contrata a Juan Lorena (19-11-01) y a Pedro Martín (7-12-01). Parece que es uno de los cuatro sacerdotes mencionados por CDD III, 1419.

59. Bartolomé Ferrero — o, mejor, herrero- $(22$ años $)$, n. de Huerta de Valdecárabos. 18-8-01: con Lope de Leiva. 2 años. 12.000 mrs. (15.1501, f. 523v). 


\section{LA GENTE DE OVANDO EN LOS PROTOCOLOS HISPALENSES}

60. Bartolomé de Riaño, toquero (San Bartolomé). 19-10-01: el toquero Pedro Fernández le paga el viaje a las Indias, las vituallas y las herramientas de su oficio, mientras que Riaño se compromete a repartir las ganancias a partes iguales. Si no hay ganancia, Riaño no está obligado a devolver ni pagar nada de lo que Fernández le ha dado y pagado; a su regreso, ha de dar buena cuenta a Fernández $(3.1501$, f. 825v).

61. Bartolomé Rodríguez (mayor de 20 años y menor de 25), trabajador, n. de Arjona. 8-10-01: con Francisco de Piédrola, n. de Arjona. 3 años. 4.000 mrs. más el $10 \%(3.1501$, f. $788 \mathrm{v})$.

62. Bartolomé Rodríguez, trabajador, marido de María Fernández (Triana). 6-12-01: con Juan de Mojados. 3 años. ¿6.000? mrs. (3.1501, f. 955r).

63. Bartolomé Sánchez Tirado, h. del hortelano Bernal Rodríguez (Omnium sanctorum). 6-9-01: con Fernando de las Maíllas. Un año. 6.000 mrs. (4.1501, f. 115v).

64. Bartolomé de Valverde (mayor de 24 años), h. de Rodrigo Albarrán, v. de Valverde. 26-10-01: con Sebastián de Guevara, v. de Lorca: 4 años. 4.000 mrs. más el $10 \%(15.1501$, f. $637 \mathrm{v})$.

65. Benito Martínez del Campo. 10-1-02: con Fernando Cerón. 3 años. 6.000 mrs. (4.1502, f. 50r).

66. Benito de Villarreal, trabajador, h. de Pedro Sánchez del Viso (m.), n. de Villarreal. 11-12-01: con Pedro de Barrera (Salvador). Por todo el tiempo que estuviere Pedro de Barrera en la Española. 3.600 mrs. más la octava parte (5.1501, f. 258v).

67. Bernardino de Sauzedo, v. de Guadalajara. 21-10-01: contrata a Pedro.

68. Bernardo de Pumarejo, n. de Pumarejo. 10-11-01: con Diego Martín y con Juan Pérez, vs. de Aranda de Duero. 3 años. 5.000 mrs. (15.1501, f. 711r).

69. Carlos de Hontiveros, v. de Hontiveros. 5-11-01: da poder a Pedro de ¿Constamina?, v. de ¿Migelhanes?, para cobrar de Pedro Sánchez de la Puebla, piloto, v. de Sevilla, 18.000 mrs. que le había dado para que le llevase algunas cosas a las Indias y no se las había llevado (15.1501, f. 678r). 9-12-01: debe a Luis de Arriaga y a Pedro de Salzedo $4.120 \mathrm{mrs}$. de dos botas de vino (15.1501, f. 770r). Contrata a Álvaro de Jerez (3-11-01), Antonio de Salamanca (3-11-01), Alonso de Escalona (3-11-01), Pedro de Torres (3-11-01), Alonso de Mondoñedo (4-11-01), Francisco de Tordesillas (4-11-01), Juan de Medina (6-11-01), Simón López (10-11-01), Simón Bermejo (10-11-01), Antón de Horozco (10-11-01), Francisco de Toledo (7-12-01) y a Pedro de Madrigal (7-12-01). El 15 de julio de 1506 entregó en la Casa de la Contratación un talegón con 252 perlas de cuenta, por el quinto de Alonso de Hojeda en Urabá (AGI Contrat. f. 97v).

70. Cebrián de Talavera (20 años), n. de Talavera. 10-11-01: con Juan de Alanís (Salvador). 2 años. 5.000 mrs. más el $10 \%$ (15.1501, f. 710r). 
71. Cristóbal Barrera, v. de Trigueros. ¿27?-11-01: de mancomún con Fernando Alonso debe a Juan de la Palma, v. de Sevilla, doce pesos por cierta ropa que les dio para su apresto en la carabela Santa María de la Rábida (maestre; Fernán Pérez, v. de Palos), ropa que iba a riesgo de Juan de la Palma: a pagar en la Española en un plazo de 20 días (4.1501, f. 137r).

72. Cristóbal de Borja (18 años), h. de Benito de Borja, v. de Bailén. ¿15?-11-01: con Luis Gudínez, v. de Bailén. 5 años. 3.500 mrs. (15.1501, f. 725r).

73. Cristóbal Fernández (mayor de 20 años y menor de 25), n. de Medellín. 5-11-01: con Gonzalo de Ocampo, v. de Cáceres. 3 años. 3.000 mrs. y el 10 $\%(3.1501$, f. $872 \mathrm{v})$.

74. Cristóbal de la Fuente, h. del carretero Juan Fernández (m.), n. de la Fuente del Maestre. 1-12-01: con el escudero Martín de Artiaga. 3 años. 6.000 mrs. (3.1501, f. 941r).

75. Cristóbal García, trabajador, marido de Violante Rodríguez (San Vicente). 4-10-01: con el albañil Francisco de Salas (San Vicente). 2 años. 8.000 mrs. (3.1501, f. 777r).

76. Cristóbal de Palacios, de color loro, criado del arzobispo de Mesina, marido de Antona García, vecina de Trigueros (condado de Niebla). 23-9-01: compra mercadería a Fernando de León (cf. Juan cuchillero). 9-11-01: debe a Juan de Mojados, h. de Pedro de Medina, notario de la Inquisición, 8.000 mrs. de mercancía que le compró "para se forneçer" para el viaje a la Española, mercancía que va cargada en la carabela La Monja (maestre: Juan Monje): a pagar en la Española en un plazo de 15 días (3.1501, f. 889r). 1-12-01: Junto con Gonzalo de Olmedo, v. de Trigueros, debe al mercader Pedro de Sanlúcar (San Isidoro), 5.500 mrs. de paño que le habían comprado, que va a riesgo de Sanlúcar en la carabela La Bachillera (maestre: Cristóbal Enríquez): a pagar en la Española en un plazo de 30 días (3.1501, f. 942r). 13-10-01: contrata a Andres García, de color loro. Se avecindó en Puerto Real (R-D 208).

77. Cristóbal de Peñalar, h. de Fernando de Peñalar (m.). 13-1-02: con el clérigo Alonso Guiral (Santa María). 4 años. 2.500 mrs. más el $10 \%$ (4.1502, f. $79 v)$.

78. Cristóbal de Piédrola (está claramente escrito "Cristóbal", no "Francisco"), v. de Arjona. 2-11-01: contrata a Cristóbal de Usagre.

79. Cristóbal de los Ríos. 9-12-01: debe a Luis de Arriaga y a Pedro de Salzedo $2.310 \mathrm{mrs}$. de una bota de vino $(15.1501$, f. $772 \mathrm{v})$. Se avecindó en la Vera Paz (R-D 230).

80. Cristóbal de Usagre, n. de Usagre, h. de Alonso Jiménez. 2-11-01: con Cristóbal de Piédrola, v. de Arjona. 3 años. 4.000 mrs. (3.1501, f. 865r).

81. Diego ***, criado del rey. 9-12-01: debe a Luis de Arriaga y a Pedro de Salzedo 4.620 mrs. de dos botas de vino (15.1501, f. 771r). 


\section{LA GENTE DE OVANDO EN LOS PROTOCOLOS HISPALENSES}

82. Diego de Azevedo, n. de La Puebla de Montalbán. 25-9-01: con el mercader Fernando de León (Santa María). 3 años. 7.000 mrs. (3.1501, f. 756r).

83. Diego de Baena, trabajador. 1-10-01: con Florencio de Anaya y Juan Mosquera (ambos vs. en San Andrés). Un año. 6.000 mrs. (4.1501, f. 216r).

84. Diego de Escobar (Omnium sanctorum). 16-11-01: se obliga a dar cuenta y razón de todas las deudas que había de cobrar en la Española al escudero García de Peralta, v. de Sanlúcar la Mayor, que le había dado poder para cobrarlas (5.1501, f. 205r). 13-12-01: junto con Alonso Rodríguez de Valdés debe a Alonso de Perona 4.000 mrs. Alzado con Francisco Roldán contra Colón en 1498 (BC I 118 [BAE 95, 317 a]), pasó con Ovando en 1502. Fue capitán de La Concepción (BC II 15 [BAE 96, 44 a]). El 18 de julio de 1506, como capitán del San Juan (maestre: Juan Vallés, v. de Palos), entregó en la Casas de la Contratación 59 marcos, siete onzas, siete ochavos y cinco tomines, equivalentes a 2.999 pesos; el 4 de diciembre de 1506 entregó 2.000 pesos, cargados en la nao de Esteban de Guecho (AGI Contrat. 4674, f. 97v, 110r). En ese mismo año hizo un contrato millonario de vino con Francisco de Riberol (Gil MyM, 155).

85. Diego Fernández, lavador de oro, marido de Isabel de Peña, v. de Trigueros. 23-9-01: compra mercadería a Fernando de León (cf. Juan cuchillero).

86. Diego García, trabajador (San Vicente), marido de *** García. i11?-9-01: debe al mercader Juan Pérez (San Vicente) 10.000 mrs. "para el fornesçimiento e basteçimiento de las vituallas *** e otras cosas convenientes e neçesarias para el viaje" a las Indias. 2 años. 10.000 mrs. García le acudirá con la mitad de lo que ganare y le devolverá los 10.000 mrs. (3.1501, f. 735r). 30-9-01: contrata a Juan Martínez.

87. Diego Gascón, aserrador, n. de O (condado de Ribagorza: ha de ser el monasterio de Nuestra Señora de la O, part. jud. de Benabarre). 6-11-01: debe $6.000 \mathrm{mrs}$. de préstamo a Fernando de Tordesillas: a pagar en la Española (15.1501, f. 685r). Se avecindó en La Sabana (R-D 236).

88. Diego Gonçales, portugués. 7-10-01: con el físico Diego Ponce (Salvador). Durante todo el tiempo que el doctor estuviere en la Española. A medias (3.1501, f. 784r).

89. Diego de Guzmán, sastre, h. de Diego de Guzmán (m.), v. de Ciudad Real. 31-7-01: con el bonetero Francisco Jiménez (Santa María). Año y medio. A medias (3.1501, f. 688r). Se avecindó en Santo Domingo (R-D 98).

90. Diego López, pintor de imágenes (Santa María). 15-10-01: con el bonetero Francisco Jiménez (Santa María). 15 meses. 12.000 mrs. (3.1501, f. 808v). ¿El v. de Salvaleón (R-D 174)?

91. Diego Marque (San Miguel). 23-12-01: debe a Juan de la Palma, v. de Trigueros, $37.000 \mathrm{mrs}$. de mercadería que va en la Santa Cruz (maestre: Andrés García Cansino): a pagar en Santo Domingo (5.1501, f. 279v, cf. 
279v). A continuación Marque consiente que el maestre tenga en su poder la dicha mercadería hasta que Juan de la Palma se dé por bien pagado de la deuda (ibidem, f. 280r). Fue dos veces por veedor: en 1493 con Colón (BC I 82 [BAE 95, 243 b]; $C D D$ III, 1419; dio nombre a un cacique, cf. HC 74 [II, 112]), y en 1502 con Ovando (BC II 42 [BAE 96, 103 b]). Regresó a España el 1 de agosto de 1506 como capitán de La Trinidad (maestre: Alonso Quintero), con 2.000 pesos para los oficiales de la Casa de la Contratación (AGI Just. 990, 2). Fue con Pedrarias Dávila como contador de Castilla del Oro (GFO [BAE XXIX 1 [119, 207 a]). Cf. Gil Conv. IV, 414-15.

92. Diego Martín, v. de Aranda de Duero. 10-11-01: contrata a Bernardo de Pumarejo. Se avecindó en Santo Domingo (R-D 161).

93. Diego Martínez, trabajador, marido de Isabel Fernández, v. de Valencina del Alcor (Aljarafe). 23-10-01: con Juan de Ortuvia. 2 años y medio. 2 ducados más el 10 \% (15.1501, f. 627r). Se avecindó en Santiago (R-D 117).

94. Diego de Nicuesa, escudero, criado de don Enrique Enríquez de Ribera. 22-11-01: junto con Francisco de Villanueva (Omnium sanctorum) debe a Juan Sánchez de la Tesorería 23.000 mrs. por la mercadería cargada en la carabela San Andrés (maestre: Martín Fernández Pacho, v. de Sevilla): a pagar en Santo Domingo (5.1501, f. 225r). 9-12-01: debe a Martín Fernández Pacho (San Andrés), maestre del San Andrés, 26.000 mrs. de mercancía, que va a riesgo de dicho maestre: a pagar en Santo Domingo (5.1501, f. 254r). 9-12-01: debe a Luis de Arriaga y a Pedro de Salzedo $2.310 \mathrm{mrs}$. de una bota de vino (15.1501, f. 770v). Contrata a Antón de Tarifa (7-10-01), Fernando López Serrano (23-11-01), Pedro Romero (23-11-01) y a García de Espinosa (20-12-01). En 1505, como capitán de una nave, entregó en la Casa de la Contratación 3.000 pesos (AGI Contrat. 4674, f. 112v); en 1507 entregó 3.000 (AGI Contrat. 4674, f. 112v). Volvió de nuevo a España como procurador de la Española en 1508, consiguiendo del rey la gobernación de Veragua (GFO XXVII 3 [BAE 117, 137ss.]). Murió, probablemente en un naufragio, en 1511 (BC II 68 [BAE 96, 168 b]).

95. Diego Ortiz, v. de Madrid. 9-12-01: junto con Alonso de Pallares, v. de Zamora, debe a Luis de Arriaga y a Pedro de Salzedo $2.320 \mathrm{mrs}$. de una bota de vino (15.1501, f. 771v). ¿El v. de Santo Domingo (R-D 164)?

96. Diego Ponce, doctor en Medicina (Salvador). 12-11-01: da poder general al canónigo maese Rodrigo de Santaella (3.1501, f. 898v). Contrata a Álvaro Gonçales (5-10-01), Pedro Gómez (7-10-01), Diego Gonçales (7-10-01) y Alonso de Lago (23-10-01). Su hermano Alonso Ponce pasó en la misma flota como cirujano (CDD III, 1419)

97. Diego Ramírez Hortelano, v. de Toledo. 9-12-01: de mancomún con Juan de Madrid debe a Luis de Arriaga y a Pedro de Salzedo 2.315 mrs. de una bota de vino (15.1501, f. 768v). ¿El v. de Salvaleón (R-D 173)? 
98. Diego Ruiz de la Muela, v. de Cuenca. 8-11-01: debe a Gonzalo Rodríguez (San Vicente) $3.200 \mathrm{mrs}$. de préstamo en mercancías y vituallas: a pagar en la Española en un plazo de 30 días (4.1501, f. 166v). 9-12-01: debe a Luis de Arriaga y a Pedro de Salzedo $1.810 \mathrm{mrs}$. de una bota de vino (15.1501, f. 770r).

99. Diego de Santiago (22 años), herrero, n. de Ampudia. 18-9-01. con Lope de Leiva, v. de Jaén. 2 años. 12.000 mrs. (15.1501, f. 523r).

100. Diego de Ulloa, v. de Zamora. 11-9-01: contrata a Alonso López.

101. Esteban de Molina, clérigo (Magdalena). 9-12-01: debe a Luis de Arriaga y a Pedro de Salzedo 2.310 mrs. de una bota de vino (15.1501, f. 771r).

102. Felipe Rodríguez, albañil. 6-12-01: contrata a Alonso Núñez.

103. Fernando del Alcázar (Santa Cruz). 20-10-01: contrata a Alonso de Toro.

104. Fernando de Almazán, h. de Alonso de Almazán, v. de Plasencia. 10-11-01: con el presbítero Martín Martínez. 2 años. 5.000 mrs. más el 10 \% (15.1501, f. 693v).

105. Fernando Alonso, h. de García Pérez, v. de Trigueros. ¿27?-11-01: de mancomún con Cristóbal Barrera debe doce pesos a Juan de la Palma.

106. Fernando de Arce, v. de la Puente de Arce (Asturias de Santillana). 8-11-01: de mancomún con su primo Juan de Arce debe a Gonzalo Rodríguez $6.400 \mathrm{mrs}$.

107. Fernando Cerón. 10-1-02: contrata a Benito Martínez del Campo. Se avecindó en San Juan de la Maguana (R-D 218).

108. Fernando de Cisneros, n. de Alba de Tormes, h. de Juan Vizcaíno. 18-11-01: con Fernando Guiral, v. de Alba de Tormes. 4 años. A medias (3.1501, f. $914 r)$.

109. Fernando García (Salvador). 17-1-02: contrata a Gonzalo de la Cava.

110. Fernando Guiral, v. de Alba de Tormes. 18-11-01: contrata a Fernando de Cisneros. Lo menciona CDD III, 1419 como uno de los cuatro sacerdotes pagados por la Corona (pero cf. Alonso Guiral).

111. Fernando de Jerez, trabajador, v. de Jerez de la Frontera. 11-11-01: con Francisco Maldonado, v. de Salamanca. 2 años. 6.000 mrs. (15.1501, f. $715 r)$.

112. Fernando de León, mercader (Santa María). 6-9-01: vende mercaderías a Francisco de Pomareda. Contrata a Diego de Azevedo (25-9-01), Francisco de Sandoval (2-10-01) y Alonso de Guadalupe (3-12-01).

113. Fernando López Serrano, v. de Torredonjimeno (Orden de Calatrava). 23-11-01: con Diego de Nicuesa. 2 años. 8.000 mrs. (5.1501, f. 225v).

114. Fernando de Lugo, v. de Sanlúcar de Barrameda. Contrata a Pedro de Busto (17-11-01), Gonzalo Eanes (17-11-01) y Martín de Salinas (20-11-01).

115. Fernando de las Maíllas. 6-9-01: contrata a Bartolomé Sánchez Tirado. Se avecindó en el Bonao (R-D 199). 
116. Fernando de Moronta, trabajador, n. de Toledo y v. de Ubeda, h. de Fernando de Moronta (m.). 2-10-01: con Gómez de Alfaro, v. de Madrid. 3 años. 6.000 mrs. mas el $10 \%$ (3.1501, f. 775r). Se avecindó en Salvaleón (R-D 172: impreso: "Marota").

117. Fernando Nieto, v. de Béjar del Castañal. 6-11-01: de mancomún con Francisco de Carmona debe a Fernando de Tordesillas, n. de Tordesillas, 9.000 mrs. de préstamo: a pagar en la Española (15.1501, f. 684r).

118. Fernando Ponce de León, h. de D. Alonso Ponce de León (m.), v. de Sevilla en San Román. 5-11-01: se obliga con Gil Martín de Olmedo (San Román) a ir de compañía a las Indias "en el armada que Sus Altezas agora enbían". Gil Martín pone quince fanegas de trigo, cinco arrobas de vino y siete reales de plata; Fernando Ponce mete las demás cosas que son menester para el viaje. De las ganancias, corresponderán tres cuartas partes a Fernando y una a Gil Martín (9.1501). Se avecindó en Santo Domingo (R-D 90). Fue testigo en el pleito que puso Alonso de Nicuesa a D. Diego Colón en 1514 (AGI Just. 1).

119. Fernando de Robles (San Marcos). 11-12-01: contrata a Miguel de Sigüenza.

120. Fernando de Tordesillas, n. de Tordesillas. 6-11-01: presta dinero a Fernando Nieto y a Francisco de Carmona. 6-11-01: presta 6.000 mrs. a Diego Gascón.

121. Fernando de Torres (mayor de 24 años y menor de 25), n. de La Hinojosa (lugar del conde de Benalcázar). 12-11-01: con el platero Álvar Díaz (Santa María). 2 años. 9.000 mrs. (5.1501, f. 195r).

122. Fernando de Villada (San Lorenzo). 11-11-01: contrata a Alonso de Paredes.

123. Florencio de Anaya (San Andrés). 1-10-01: contrata a Diego de Baena.

124. Francisco (mayor de 16 años y menor de 25), h. de Gonzalo García (m.) y de Isabel García (San Pedro). 23-11-01: con Luis de Quesada (Santa María la Blanca). 3 años. 10.000 mrs. (5.1501, f. 226v).

125. Francisco frutero, h. del frutero Bartolomé Sánchez (Salvador). 4-9-01: con el sillero Rodrigo de Lepe. Por todo el tiempo que Lepe estuviere en las Indias. 5.000 mrs. $(4.1501$, f. 101v).

126. Francisco de Aranda, tejedor de seda, n. de Toledo, h. de Juan de Aranda (m.). 11-11-01: con Gonzalo de Ocampo, v. de Cáceres. 3 años. 3.000 mrs. más el $10 \%$ (3.1501, f. 892v).

127. Francisco de Carmona, trabajador, h. de Alonso Sánchez (m.), v. de Carmona (San Pedro). 23-9-01: compra mercadería a Fernando de León (cf. Juan cuchillero).

128. Francisco de Carmona (¿el anterior?). 6-11-01: de mancomún con Fernando Nieto debe 9.000 mrs. a Fernando de Tordesillas. ¿El v. de La Vera Paz (R-D 234?). 


\section{LA GENTE DE OVANDO EN LOS PROTOCOLOS HISPALENSES}

129. Francisco de Fuentes, h. de Pedro de Fuentes (San Juan). Contrata a Juan Ruiz (29-10-01) y a Juan de Ponferrada (5-11-01). ¿El v. de Lares de Guahaba (R-D 211) o el testigo en La Vega en el pleito que puso Alonso de Nicuesa a D. Diego Colón en 1514 (AGI Just. 1)?

130. Francisco García, h. de Juan Lozano Peinado, v. de Ciudad Rodrigo. 8-11-01: con el presbítero Martín Martínez. 2 años. 4.000 mrs. más el $10 \%$ (15.1501, f. 689r).

131. Francisco de Godoy. 25-10-01: contrata a Antón Bravo.

132. Francisco González, trabajador, h. de Francisco González, trabajador, v. de Valencia de Alcántara. 20-10-01: con el clérigo Alonso Fernandez. 2 años. $5.000 \mathrm{mrs}$. (15.1501, f. 616v).

133. Francisco de Hoz. 8-11-01: saca a paz y a salvo al maestre Francisco García, v. de Palos, maestre de la carabela La Garza, del préstamo de $5.000 \mathrm{mrs}$. que por él había tomado García de Pero López de Sevilla (5.1501, f. 185r, cf. f. 204r).

134. Francisco Jiménez, bonetero (Santa María). 19-10-01: presta a Alonso de ¿Entrán? quince pesos de oro: a pagar en la Española en un plazo de veinte días (3.1501, f. 819v). 11-11-01: hace compañía con Juan de Mojados (3.1501, f. 889v). Contrata a Diego de Guzmán (31-7-01), Juan de las Casas (31-7-01), Alonso de Carrión (15-10-01), Diego López (15-10-01), Marcial de Movellán (15-10-01) y Juan de Valladolid (23-11-01).

135. Francisco Jiménez, v. de Ledesma, tundidor (mayor de 24 años y menor de 25). 13-12-01: hace compañía con Alonso Manuel de Lando para trabajar en las Indias.

136. Francisco de Leanca (¿Luanca?), h. de Pero González del Castillo (m.). 13-1-02: con el clérigo Alonso Guiral (Santa María). 4 años. 2.500 mrs. más el $10 \%(4.1502$, f. $79 \mathrm{v})$.

137. Francisco Maldonado, v. de Salamanca. 11-11-01: contrata a Fernando de Jerez.

138. Francisco Mogollón, h. de Lorenzo Mogollón, v. de Cáceres. 26-10-01: hace compañía para Indias con García Sánchez, v. de Las Garrovillas (15.1501, f. 636r).

139. Francisco de Montemolín, h. de Alonso Fernández de Montemolín, v. de Montemolín. 12-1-02: con Juan Mosquera, v. de Sevilla. 3 años. 6.000 mrs. (4.1502, f. 75v).

140. Francisco de Piédrola, n. de Arjona. Contrata a Bartolomé Rodríguez (8-10-01) y Juan de Tamayo (8-10-01). Fue como alcaide (CCD III, 1418). Volvió de la Española como capitán de nave: el 29 de octubre de 1505 entregó 12.000 pesos de oro en la Casa de la Contratación (AGI Contrat. 4674, f. $75 \mathrm{r}$ ).

141. Francisco de Pomareda (Santa María), h. de Pedro de Pomareda (m.), marido de Francisca de Hojeda. 6-9-01: debe al mercader Fernando de León 
(Santa María) 3.000 mrs. de cierta mercadería que le compró: a pagar en la Española en un plazo de quince días (3.1501, f. 714v). 6-9-01: debe 1.600 mrs. al mercader Fernando de León: a pagar en la Española en un plazo de quince días y, si no fuere en ese viaje, en Sevilla en un plazo de seis meses (3.1501, f. 783v). 10-1-02: presta a Pedro de Sanlúcar cinco ducados para su pasaje y manutención a la Española. 16-1-02: debe a *** (¿Diego?) de Escobar (Omnium sanctorum) 1.400 mrs. (una deuda de Pomareda a Pero Ruiz que había saldado Escobar): a pagar en la Española en un plazo de 30 días $(4.1502$, f. 107v). 16-1-02: da poder general a su mujer, Francisca de Hojeda (4.1502, f. 108r). 22-1-02: hizo testamento antes de partir a las Indias. Dispuso que lo enterrasen en San Francisco, en la sepultura que allí tenía. Dejó por heredero a su h. Alonso de Hojeda. Nombró albaceas a maestre Francisco boticario, v. de Granada, y a su mujer (4.1502, f. 121v).

142. Francisco de Rojas, tejedor (San Lorenzo). 20-9-01: Contrata a Juan de Rojas y Alonso de Argüello.

143. Francisco de Salas, albañil (Omnium sanctorum). Contrata a Antón Vázquez (30-9-01), Cristóbal García (4-10-01), Pedro Fernández (7-10-01) y Alonso Tamariz (19-10-01).

144. Francisco Sánchez de Marchena, trabajador (Triana). 15-11-01: con Juan de Mojados. 2 años y medio. 8.000 mrs. (3.1501, f. 904v).

145. Francisco de Sandoval, platero, h. de Alonso de Pastrana, v. de Castrojeriz. 2-10-01: con el mercader Fernando de León (Santa María). 3 años. 7.000 mrs. (3.1501, f. 773r).

146. Francisco de ¿Soreta?, v. de Alcalá de Henares. 4-11-01: contrata a Pedro Díaz de las Cuevas.

147. Francisco de To*** (¿Toledo? ¿Tordesillas?), v. de Ribera. 9-12-01: debe a Luis de Arriaga y a Pedro de Salzedo $1.810 \mathrm{mrs}$. de una bota de vino $(15.1501$, f. $771 \mathrm{v})$.

148. Francisco de Toledo, n. de Madrigal. 7-12-01: con Carlos de Hontiveros. 3 años. 10.000 mrs. (15.1501, f. 760r).

149. Francisco de Tordesillas, h. de Juan Alonso de Tordesillas, v. de Tordesillas. 4-11-01: con Carlos de Hontiveros. 3 años. 8.000 mrs. (15.1501, f. 676v). Se avecindó en Santiago (R-D 121).

150. Francisco de Valdelalosa (mayor de 20 años), n. de Valdelalosa. 7-12-01: con Lope de Leiva, v. de Córdoba. 2 años. 8.000 mrs. (15.1501, f. 762v). El contrato fue repetido en el f. 763v por inadvertencia del escribano.

151. Francisco de Valdés, escudero, h. de Pero Fernández de Valdés (Magdalena) 10-1-02: debe a Catalina Fernández, viuda de Alonso Gómez (Magdalena), 1.450 mrs. que Valdés debía a Alonso Gómez, su marido, y que había cobrado por él de Francisco de Fonseca: a pagar en la Española, en un plazo de seis meses desde que llegase a dicha isla el navío de Francisco Quintero, v. de Palos (4.1502, f. 54v). 


\section{LA GENTE DE OVANDO EN LOS PROTOCOLOS HISPALENSES}

152. Francisco de Villanueva (Omnium sanctorum). 23-11-01: junto con Diego de Nicuesa debe a Juan Sánchez de la Tesorería 23.000 mrs. por la mercadería cargada en la carabela San Andrés (5.1501, f. 225r).

153. Francisco de Zurita, v. de Alcalá de Henares. 25-10-01: contrata a Juan de Saldaña.

154. Frutos de Deleitosa, estante en las guardias de los reyes. Junto con Juan de Ortuvia, criado del adelantado de Murcia, y Alonso de Castro, v. de Jaén, debe a Juan de Mojados 16.575 mrs. por mercaderías que le habían comprado, que van a riesgo de Juan de Mojados en la carabela Colina (maestre: Bartolomé Colín, v. de Palos): a pagar en la Española en un plazo de quince días (3.1501, f. 922r). 15-11-01: en nombre de su primo Gaspar de Deleitosa, v. de Campanario, hace procurador sustituto a Juan de Mojados para cobrar deudas que se le debían a Gaspar (3.1501, f. 923r). Contrata a Juan de Ocaña (2-11-01) y a Pedro Martín (11-11-01).

155. García de Espinosa, h. de Pedro de Espinosa (m.), n. de Torredonjimeno. 20-12-01: con Diego de Nicuesa. 2 años. 8.000 mrs. (5.1501, f. 271r).

156. García Sánchez, h. de Juan Rodríguez, v. de Las Garrovillas. 26-10-01: hace compañía para Indias con Francisco Mogollón.

157. Gil Delgado, v. de Jerez de la Frontera. 9-12-01: debe a Luis de Arriaga y a Pedro de Salzedo 4.120 mrs. de dos botas de vino (15.1501, f. 770r).

158. Gil López, trabajador, v. de Medellín: 25-10-01: con Lope de Medina, v. de Medina Sidonia. 3 años. 4.000 mrs. más el $10 \%$ (15.1501, f. 634r).

159. Gil Martín de Olmedo (San Román). 5-11-01: hace compañía con Fernando Ponce de León.

160. Gómez de Alfaro, v. de Madrid. Contrata a Fernando de Moronta (2-10-01), Juan Merino (19-10-0179), Antón Mallorquín (27-10-01), Alonso Martín (9-11-01), Juan de Vadillo (9-12-01) y *** (9-12-01).

161. Gómez de Sauzedo, v. de Villafrecha, mayor de 22 años y menor de 25. 25-9-01: compra mercaderías al mercader Fernando de León (cf. Alonso Gutiérrez de Villanueva).

162. Gonzalo (24 años), criado del mercader Juan Bautista Cerezo. 16-10-01: con Juan de Saravia. 6.000 mrs. más el $10 \%$ (15.1501, f. 604v).

163. Gonzalo de la Cava, h. de Gonzalo Rodríguez de la Cara [sic] (m.), v. de Utrera.17-1-02: con Fernando García (Salvador). 2 años. 7.000 mrs. (4.1502, f.112r).

164. Gonzalo Eanes, portugués, v. de Granada. 17-11-01: con Fernando de Lugo. 2 años. 7.500 mrs. más el $10 \%$ (5.1501, f. 210v).

165. Gonzalo de Ocampo, v. de Cáceres. 9-11-01: debe a Luis de Arriaga y a Pedro de Salzedo 3.620 mrs. de dos botas de vino (15.1501, f. 770v). Contrata a Cristóbal Fernández (5-11-01), Francisco de Aranda (11-11-01), Mateo (11-11-01), ¿Pedro de Montesdoca? (9-12-01), Pedro Martín (9-1201), Pedro de Utrera (9-12-01), Jorge (9-12-01) y Cristóbal Fernández 
(5-11-01). Se avecindó en la Buenaventura (R-D 186, cf. G-F I, 316). Firmó a fines de 1517 un memorial dirigido al rey con otros vs. de Santo Domingo (G-F II, 133). Fue capitán de una armada de castigo contra los indios de Tierra Firme en 1520 (BC III 156[BAE 95, 555ss.]; GFO XIX 4 [BAE 118, 197b]; G-F II, 1138). Testificó en 1521 en la información de Bastidas (G-F II, 1015).

166. Gonzalo de Olmedo, v. de Trigueros. 1-12-01: junto con Cristóbal de Palacios, loro, v. de Trigueros, debe al mercader Pedro de Sanlúcar 5.500 mrs.

167. Gonzalo Rodríguez (San Vicente). 8-11-01: presta 3.200 mrs. a Diego Ruiz de la Muela.

168. Gonzalo Suárez (San Julián). 9-12-01: de mancomún con Juan de Molina compra vino a Luis de Arriaga y a Pedro de Salzedo por valor de $4.125 \mathrm{mrs}$.

169. Gutierre Bezerra (Omnium sanctorum). 9-12-01: debe a Luis de Arriaga y a Pedro de Salzedo 4.620 mrs. de dos botas de vino (15.1501, f. 770r).

170. Jerónimo de Herrera, v. de Córdoba. 9-12-01: junto con Luis Moyano, v. de Córdoba, debe a Luis de Arriaga y a Pedro de Salzedo $1.810 \mathrm{mrs}$. de una bota de vino (15.1501, f. 771v). Se avecindó en San Juan de la Maguana (R-D 221).

171. Jerónimo de Valenzuela, v. de Córdoba. 9-12-01: debe a Luis de Arriaga y a Pedro de Salzedo 4.125 mrs. de dos botas de vino $(15.1501$, f. $769 \mathrm{v})$.

172. Jorge Ve***, marido de Beatriz Alonso. 9-12-01: con Gonzalo de Ocampo, v. de Cáceres. 3 años. 6.000 mrs. más el $10 \%$ (3.1501, f. 963r).

173. Juan cuchillero, marido de Leonor de Marchena (Triana). 23-9-01: de mancomún con Juan de Leguizamo (San Bartolomé), Juan del Castillo, escudero, Cristóbal de Palacios, de color loro, Diego Fernández, lavador de oro, v. de Trigueros, y Francisco de Carmona, trabajador, v. de Carmona (San Pedro), debe al mercader Fernando de León (Santa María), 17.200 mrs. de mercadería que le compraron: a pagar en la Española en el plazo de quince días y, si no fueren en ese viaje, en Sevilla en un plazo de dos meses (3.1501, f. 745r).

174. Juan de Aguilar, h. de Pedro de Aguilar, v. de Toro. 14-1-02: con Juan Carrillo, v. de Toledo. Un año y medio. 6.000 mrs. en total más el $10 \%$ (4.1502, f. 93v).

175. Juan de Alanís (Salvador). 10-11-01: contrata a Cebrián de Talavera. Se avecindó en Puerto Real (R-D 205).

176. Juan Álvarez de Gijón (escrito en la primera escritura "Gigon”), v. de Valladolid. 23-9-01: contrata a Alonso Montañés y a Juan Gallego. 9-12-01: debe a Luis de Arriaga y a Pedro de Salzedo 2.310 mrs. de una bota de vino $(15.1501$, f. $768 v)$.

177. Juan de Arce, v. de la Puente de Arce (Asturias de Santillana). 8-11-01: de mancomún con su primo Fernando de Arce debe a Gonzalo Rodríguez (San 


\section{LA GENTE DE OVANDO EN LOS PROTOCOLOS HISPALENSES}

Vicente), maestre de la carabela Santa Catalina, 6.400 mrs. que les prestó para comprar mercancías y vituallas, que van a riesgo de Gonzalo Rodríguez: a pagar en la Española en un plazo de 30 días (4.1501, f. 166r).

178. Juan de Astorga (20 años), h. de Cristóbal Álvarez, v. de Astorga. 10-11-01: con Juan de Saravia (San Nicolás). 2. años. 5.500 mrs. (15.1501, f. 692v).

179. Juan Barba (San Esteban), h. del veinticuatro Juan Barba y de doña Mayor Osorio (ms.). 11-1-02: de mancomún con Alonso Fernández Melgarejo, h. de Pedro de Urrea (San Román), debe a Tomás de Palenzuela 21.000 mrs. de 18 quintales de aceite para cargar en la nao de Peñafiel, de los cuales la mitad va a riesgo de Palenzuela y la otra mitad a ventura de Barba y Fernández: a pagar en Santo Domingo en un plazo de 31 días (4.1502, f. 57v). 29-10-01: contrata a Miguel Esteban. Se avecindó en Santiago (R-D 117).

180. Juan de Berlanga, v. de Burgo de Osma. 18-11-01: de mancomún con Juan de Berlanga, v. de Burgo de Osma, debe $3.200 \mathrm{mrs}$. al herrero Juan de Monleón por compra de herramientas.

181. Juan de Brizuela. 16-8-01: con Antón García de Buitrago. 2 años. 8.000 mrs. (3.1501, f. 644r).

182. Juan Caballos (mayor de 20 años y menor de 25), n. de Cáceres, h. de Alonso Caballos, tintorero, v. de Cáceres. 2-11-01: con Alonso Guiral (Santa María). 5 años. 5.000 mrs. más el $10 \%$ (3.1501, f. 864r). ¿Será "Çaballos", esto es, Ceballos, pudiéndose identificarlo entonces con el v. de Santo Domingo (R-D 166)?

183. Juan Caro, h. de Beatriz Rodríguez, marido de Francisca de Medina (San Lorenzo). 11-1-02: hizo testamento antes de partir a las Indias. El armero Contreras le debía 1.730 mrs. por Jerónimo Rodríguez, herrador, y el arrendador Juan de Vargas 700 mrs. para cumplimiento de 2.000 mrs. que había ganado de pujas en la imposición de las curtidurías de 1501. Mandó que, de fallecer en Sevilla, lo enterrasen en San Francisco, en la sepultura que allí tenía. Dejó las arras a su mujer, 420 mrs. al canónigo doctor Alcocer y 4.000 mrs. a su sobrina Isabel, hija de su hermano Rodrigo Caro, para ayuda a su casamiento. Ahorró a su esclavo Juanico, a condición de que sirviera quince años a su mujer. Dejó por heredera a su madre. Nombró albaceas a su hermano Diego Caro y a Alonso de Medina, su cuñado (4.1502, f. 63v).

184. Juan Carrillo, v. de Toledo. 14-1-02: contrata a Juan de Aguilar y a Juan de Salazar. ¿Juan Carrillo Mexía, el regidor de Santiago (R-D 111)?

185. Juan de las Casas, sastre, h. de Juan de las Casas (m.), estante en Sevilla. 31-7-01: con el bonetero Francisco Jiménez. Año y medio. 10.000 mrs. (3.1501, f. 688v).

186. Juan del Castillo, escudero, h. de Antonio lombardero (m.), v. de Lérida. 23-9-01: compra mercadería a Fernando de León. Cf. Juan cuchillero. 
187. Juan de Celaya, v. de Aranda de Duero. 7-1-02: debe al trapero Pero Rodríguez (Santa María), 27.000 mrs. por el vino blanco yema que le había comprado: a pagar en la Española en un plazo de 30 días desde que llegasen "los navíos del armada que agora va en la capitanía del comendador de Lares, governador de la isla Española" (4.1502, f. 35r).

188. Juan de Espinosa, h. de Juan Marano (¿Marrano?), n. de Espinosa de los Monteros. 18-1-02: con Andres Cutiño, v. de Ávila. 3 años. 6.000 mrs. más el 10 \% (4.1502, f. 116v). Se avecindó en Lares de Guahaba (R-D 215).

189. Juan de Esquivel. Contrata a Pedro de Asturias (sin fecha). Fue con Colón en 1493 y con Ovando en 1502. En 1504 volvió a la Península como procurador de la Española, para pedir al rey que no se le pagase más del quinto (BC II 6 [BAE 96, 22 b]). Hizo después una larga carrera en Indias: de capitán general en la Española con Ovando (BC II 8ss. [BAE 96, 25 a]) a teniente de gobernador y fundador de Sevilla la Nueva en Jamaica con Diego Colón (BC II 52 [129 a]; GFO XVIII 1 [II, 184 b]).

190. Juan de Gálvez (mayor de 22 años y menor de 25), barbero, h. de Juan de Gálvez (m.), v. de Llerena. 7-10-01: con el platero Álvar Díaz (Santa María). Un año y medio. $10.000 \mathrm{mrs}$. (5.1501, f. 182v).

191. Juan Gallego, n. de La Coruña. 23-9-01: con Juan Álvarez de Gijón, v. de Valladolid. 3 años y aún más, si Juan Álvarez estuviere más tiempo en las Indias. $5.000 \mathrm{mrs}$. (4.1501, f. 183v).

192. Juan García, barbero (San Juan). 22-11-01: de mancomún con el barbero Alonso García (Santa María) debe a Juan Sánchez de la Tesorería 12.255 mrs. de cierta mercadería cargada en la carabela La Monja (maestre: Martín Monje, v. de Palos): a pagar en Sevilla o en Cádiz (5.1501, f. 220r).

193. Juan García de Cebreros, v. de Cebreros. 9-12-01: debe a Luis de Arriaga y a Pedro de Salzedo 1.810 mrs. de una bota de vino (15.1501, f. 772v).

194. Juan Gil, v. de Cádiz. 9-12-01: debe a Luis de Arriaga y a Pedro de Salzedo 1.810 mrs. de una bota de vino $(15.1501$, f. $769 v)$. Partió el 28 de marzo de 1507 como capitán de la nao de Pedro de Arbolancha (maestre: Antón García, v. de Moguer), con 2.000 pesos para los oficiales de la Casa de la Contratación (AGI Just. 990, 2).

195. Juan Gutierre, v. de Jaén. 9-12-01: debe a Luis de Arriaga y a Pedro de Salzedo $1.810 \mathrm{mrs}$. de una bota de vino (15.1501, f. 769v). ¿El Juan Gutiérrez v. de San Juan de la Maguana (R-D 220)?

196. Juan de Leguizamo, criado de Juan de Valtierra (San Bartolomé). 23-9-01: compra mercadería a Fernando de León. Cf. Juan cuchillero.

197. Juan Lorena (20 años), trabajador, n. de Torrejoncillo (Coria de Galisteo). 19-11-01: con Atanasio Pedro Díaz de la Costana (Azuaga, maestrazgo de Santiago). 3 años. 20 ducados más el $10 \%$ (15.1501, f. 750r). ¿El Juan de Loreda v. del Bonao (R-D 201)? 


\section{LA GENTE DE OVANDO EN LOS PROTOCOLOS HISPALENSES}

198. Juan de Madrid, pastelero, v. de Madrid. 9-12-01: de mancomún con Diego Ramírez Hortelano compra vino a Luis de Arriaga y a Pedro de Salzedo por valor de 2.315 mrs. Se avecindó en La Buenaventura (R-D 193).

199. Juan Marquesín, v. de Alcalá de Henares. 26-11-01: debe al barbero Juan García (San Juan) 1.850 mrs. de la mercadería que García había comprado a Alonso de Perona (por la cual se había obligado Juan García con Perona), que va en la carabela La Monja (maestre: Martín Monje, v. de Palos): a pagar en Sevilla o en Palos (5.1501, f. 228r). Avecindado en Santo Domingo (R-D 150), firmó a fines de 1517 un memorial dirigido al rey con otros vs. de la ciudad (G-F II, 133).

200. Juan Martín de Beas, trabajador (Triana). :11?-9-01: debe 10.000 mrs. al mercader Juan Pérez (San Vicente). 2 años. 10.000 mrs. Juan Martín le acudirá con la mitad de lo que ganare y le devolverá los 10.000 mrs. (3.1501, f. $736 v)$.

201. Juan Martínez, portugués, trabajador (San Vicente). 30-9-01: con el trabajador Diego García (San Vicente). 2 años. Pide en pago de sus servicios "un capuz e dos sayos e dos jubones e tres camisones e quatro pares de alpargates e un bonete e un puñal". A medias $(4.1501$, f. $210 \mathrm{v})$.

202. Juan de Medina, n. de Medina de Rioseco. 22-11-01: con Sebastián de Valencia, v. de Valencia. 2 años y medio. 7.000 mrs. (3.1501, f. 925v).

203. Juan de Medina, v. de Medina de Pomar. 6-11-01: con Carlos de Hontiveros. 3 años. 10.000 mrs. (15.1501, f. 680r).

204. Juan Merino, n. de Ávila, h. de Antón Fernández Merino. 19-10-01: con Gómez de Alfaro, v. de Madrid. 5 años. 6.000 mrs. (3.1501, f. 825r).

205. Juan de Mojados (mayor de 18 años y menor de 25), hijo del notario de la Inquisición Pedro de Medina. 23-9-01: presta 8.000 mrs. en mercancías a Cristóbal de Palacios. 11-11-01: presta 1.470 mrs. a Marcial de Movellán. 12-11-01: presta 1.360 mrs. a Juan de Tajuste. 15-11-01: es nombrado procurador de Gaspar de Deleitosa. 22-11-01: vende 16.575 mrs. en mercaderías a Frutos de Deleitosa, Juan de Ortuvia y Alonso de Castro. 11-11-01. Hace compañía con el bonetero Francisco Jiménez (3.1501, f. 889v). Contrata a Francisco Sánchez de Marchena (15-11-01), Pedro Jiménez de Utrera (4-12-01) y Bartolomé Rodríguez (6-12-01).

206. Juan de Molina (San Bartolomé, Santa María la Blanca), escudero, criado que fue de García Tello, marido de Leonor Martel. Ovando lo nombró alguacil mayor de las Indias (lo era en 1506). 6-10-01: debe a Alonso de Perona $7.200 \mathrm{mrs}$. de mercancía que le había comprado, que iba a riesgo de Perona en la nao Santo Domingo (maestre: Juan de Peñafiel [Triana]): a pagar en Sevilla (5.1501, f. 251r). A continuación avala Peñafiel a Molina, y Molina se obliga a sacarlo a paz y a salvo (ibidem, f. 251v). 9-12-01: de mancomún con Gonzalo Suárez (San Julián) debe a Luis de Arriaga (Santa María) y a 
Pedro de Salzedo, v. de la Española, $4.125 \mathrm{mrs}$. de dos botas de vino, que iban en la nao Santo Domingo (maestre: Peñafiel [Triana]): a pagar en la Española (15.1501, f. 768r). 11-1-1502: debe a Tomás de Palenzuela 9.000 mrs. que le había prestado para comprar mercadería para la nao de Peñafiel, de la cual mercadería la mitad va a riesgo de Molina y la otra mitad a ventura de Palenzuela: a pagar en Santo Domingo en un plazo de 31 días (4.1502, f. 63r). 10-10-1505: como capitán de la nave de que era maestre Bartolomé Rodríguez entregó en la Casa de la Contratación 159 marcos, siete onzas, dos ochavos y tres tomines, equivalentes a 8.000 pesos (AGI Contrat. 4674, f. 86v). 8-11-06: Leonor Martel, su mujer, da poder al procurador Hernardo de Sarabia para cobrar en su nombre y en el de su marido (APS IX 1506 [= 17431]).

207. Juan de Monleón, herrero (San Juan). 18-11-01: vende 300 herramientas por 3.200 mrs. a Rodrigo de Alburquerque y a Juan de Berlanga. 9-12-01: debe a Luis de Arriaga y a Pedro de Salzedo $1.810 \mathrm{mrs}$. de una bota de vino (15.1501, f. 771r).

208. Juan de Mosquera (San Andrés). Contrata a Diego de Baena (1-10-01), Juan de Toro (12-1-02) y Francisco de Montemolín (12-1-02). Se avecindó en Santo Domingo (R-D 139), donde llegó a ser alcalde. Testificó en la información de 1516 (G-F I, 314). Fue tutor de los hijos de Francisco de Garay (AGI Just. 5, 1).

209. Juan de la Nava, n. de La Nava (Medina del Campo), h. de Juan Sánchez (m.). 9-12-01: con Alonso de ¿Moriana? (Baeza). 3 años. *** mrs. (3.1501, f. $965 \mathrm{v})$.

210. Juan de Ocaña (24 años), trabajador, v. de Ocaña. 2-11-01: con Frutos de Deleitosa. 4 años. 9.000 mrs. (15.1501, f. 653v).

211. Juan de Ortuvia, criado del adelantado de Murcia, Pedro Fajardo. 22-11-01: con Frutos de Deleitosa y Alonso de Castro compra mercaderías a Juan de Mojados. 23-10-01: contrata a Diego Martínez.

212. Juan Patiño (Santa María). 19-10-01: contrata a Alonso Martín Riero.

213. Juan Pérez, v. de Aranda de Duero. 10-11-01: contrata a Bernardo de Pumarejo.

214. Juan Pérez Valenciano, h. de Juan Pérez (m.), n. de Valencia "de Aragón". 4-9-01: con el sillero Rodrigo de Lepe (Santa María). 2 años. 10.000 mrs. $(4.1501$, f. $100 \mathrm{v})$.

215. Juan de Ponferrada, h. de Gómez de Arias, v. que fue de Ponferrada (m.). 5-11-01: con Francisco de Fuentes (San Juan). 3 años. 6.000 mrs. y el $10 \%$ (9.1501).

216. Juan Rodríguez, h. de Gil Fernández, v. de Cambil (Jaén). 26-11-01: con Ruy Páez de Sotomayor, v. de Jaén. Por todo el tiempo que éste estuviere en las Indias. 5.000 mrs. (4.1501, f. 168v). ¿El v. de Santo Domingo (R-D 165)? 


\section{LA GENTE DE OVANDO EN LOS PROTOCOLOS HISPALENSES}

217. Juan de Rojas (San Lorenzo). 20-9-01: con el tejedor Francisco de Rojas (San Lorenzo). 2 años. 8.000 mrs. (4.1501, f. 202r).

218. Juan de Rojas (¿el anterior?), tejedor de lienzos (San Bartolomé). 17-1-02: debe al curtidor Pedro Arias (San Vicente), 5.180 mrs. por la mercadería que había cargado en la nao de Juan de Peñafiel, mercadería que va a riesgo de Arias: a pagar en la Española en un plazo de seis meses (4.1502, f. 118v). Ha de ser el v. de Santo Domingo (R-D 144) o el de Villanueva de Yáquimo (R-D 246).

219. Juan Ruiz, trabajador, marido de Elvira Martín (Santa Catalina). 29-10-01: con Francisco de Fuentes, h. de Pedro de Fuentes (San Juan). 2 años. 9.000 al año (9.1501). ¿El v. de San Juan de la Maguana (R-D 224?)?

220. Juan de Salamanca. 22-9-01: contrata con Juan de Villa a Pedro del Rebollar.

221. Juan de Salazar, n. de Villalón. 14-1-02: con Juan Carrillo, v. de Toledo. 3 años. 5.000 mrs. más el $10 \%$ (4.1502, f. 94r).

222. Juan de Saldaña (24 años), v. de Saldaña. 25-10-01: con Francisco de Zurita, v. de Alcalá de Henares. 3 años. 7.000 mrs. más el $10 \%$ (15.1501, f. 631r).

223. Juan de Saravia, h. de Francisco de Saravia (alcalde de los hombres de a caballo de Sevilla). Contrata a Pedro (16-10-01), Gonzalo (16-10-01) y Martín de Salinas (20-11-01).

224. Juan de Tahuste (o Tajuste), v. de Baeza. 12-11-01: debe a Juan de Mojados $1.360 \mathrm{mrs}$. de mercadería que va a bordo de El Espíritu Santo (maestre: Diego Rodríguez, v. de Triana): a pagar en la Española (15.1501, f. 718r). 1-12-01: debe a Juan de Mojados 1.360 mrs. por mercaderías que van a riesgo de Mojados en la misma carabela El Espíritu Santo: a pagar en la Española en un plazo de 15 días (3.1501, f. 943r).

225. Juan de Tamayo, n. de Piedrahita. 8-10-01: con Francisco de Piédrola, n. de Arjona. 3 años. $6.000 \mathrm{mrs}$. (3.1501, f. 789v).

226. Juan de Toro, h. de Rodrigo Díaz, v. de Toro. 12-1-02: con Juan de Mosquera, v. de Sevilla. 2 años. 6.000 mrs. (4.1502, f. 75r).

227. Juan de Tórtola, v. de Tórtola. 24-12-01: hace una compañía con Fernando de Cazalla (San Vicente), que lo abastece y pertrecha: van a medias (5.1501, f. 281r).

228. Juan de Vadillo, n. de Vadillo, h. de Juan de Valladolid. 9-12-01: con Gómez de Alfaro, v. de Madrid. 3 años. *** mrs. más el $10 \%$ (3.1501, f. 965r).

229. Juan de Valladolid, trabajador, h. de Fernando Rodríguez, v. de Bamba. 23-11-01: con el bonetero Francisco Jiménez. 3 años. 6.666 mrs. (3.1501, f. $926 \mathrm{v})$.

230. Juan de Villa. 22-9-01: de mancomún con Juan de Salamanca contrata a Pedro del Rebollar.

231. Juan de Zamora, trabajador, v. de Zamora. 8-11-01: con el presbítero Martín Martínez. 2 años. 6.000 mrs. más el $10 \%$ (15.1501, f. 689r). 
JUAN GIL

232. Lope Alvarez, v. de Ciudad Real. 11-11-01: contrata a Alonso de Paredes.

233. Lope de Leiva, v. de Córdoba (¿el siguiente?). 7-12-01: contrata a Francisco de Valdelalosa. 9-12-01: debe a Luis de Arriaga y a Pedro de Salzedo 3.620 mrs. de dos botas de vino (15.1501, f. 769r).

234. Lope de Leiva, v. de Jaén (¿el anterior?). 18-9-01: contrata a Diego de Santiago y a Bartolomé Ferrero.

235. Lope de Medina, v. de Medina Sidonia. 25-10-01: contrata a Gil López.

236. Lorenzo de Anaya (Omnium sanctorum). 24-9-01: junto con su hermano Luis de Anaya (Salvador) debe al mercader Fernando de León (Santa María) 5.537 mrs. y medio de compra de mercancías: a pagar en las Indias en un plazo de quince días y, si no fueren en ese viaje, en Sevilla en un plazo de seis meses (3.1501, f. 750r). Fue v. de San Juan de la Maguana (R-D 219).

237. Luis de Anaya (Salvador). 24-9-01: de mancomún con su hermano Lorenzo de Anaya compra mercancías al mercader Fernando de León.

238. Luis de Arriaga (San Lorenzo), v. de Berlanga. 31-7-01. Sebastián de Atodo, escudero del comendador Pedro de Cabrera (Santa María la Blanca), da poder a Luis de Arriaga para reclamar al "contador de las cosas tocantes a las Yndias del mar Oçéano çierto brasil" de que le habían hecho merced los reyes $(4.1501$, f. $406 \mathrm{v})$. Parece que se ha de identificar con el v. de la Vega de la Concepción citado por Las Casas (II 52 [BAE 96, 127 b]), que pasó en 1493. 26-11-01: debe a Álvar Alonso Rascón, v. de Palos, 22.500 mrs. de cierto pescado y dinero que de él recibió para el despacho de la carabela *** (maestre: Martín Domingo, v. de Palos), que iban a riesgo de Álvar Alonso Rascón: a pagar en la Española a Andrés García Cansino, v. de Palos, maestre de la carabela Santa Cruz, en un plazo de 30 días (4.1501, f. 136r). 9-12-01: de mancomún con Pedro de Salzedo vende vino a Juan Álvarez de Gijón, Juan de Molina-Gonzalo Suárez, Diego de Nicuesa, Carlos de Hontiveros, Gonzalo de Ocampo, Juan de Molina, Diego Ramírez Hortelano-Juan de Madrid, Juan de Madrid, Antón ***, Lope de Leiva, García de Buitrago, Pedro de Ávila, Juan Gutierre, Jerónimo de Valenzuela, Juan Gil, Alonso Tejeiro, Diego Ruiz de la Muela, Gutierre Bezerra, Gil Delgado, Álvar Pérez de ¿Incuestes?, Rodrigo Mexía, Diego ***, Pedro Bonifaz, Juan de Monleón, Pedro Sánchez Villar, Jerónimo de Herrera, Luis Moyano, Diego Ortiz-Alonso de Pallares, Antonio de Aguilar, Sancho de Santisteban, Pedro de ***, Esteban de Molina, Pedro de Bruxeles, Francisco de To***, Cristóbal de los Ríos y Juan García de Cebreros. Fue en 1493 con Colón (BC I 82 [BAE 95, 244 b]), que lo nombró alcaide de la fortaleza de la Magdalena (BC I 110 [300 a], llamándolo "Artiaga", al igual que HC 61 [II, 49; pero "Ariaga" en 50]). Hizo una capitulación con los reyes para poblar cuatro villas en la Española con 200 matrimonios (BC II 6 [BAE 96, 21-22]; Gil MyM 381-83), pero sólo pudo llevar con Ovando 73 parejas (CDD III, 1419). 


\section{LA GENTE DE OVANDO EN LOS PROTOCOLOS HISPALENSES}

239. Luis de Avila, h. de Juan Fernández Pacho (m.) y de Catalina Núñez (San Andrés). 4-1-02: hizo testamento antes de partir a las Indias. Primero enumeró a sus deudores: Francisco de Villanueva (Omnium sanctorum) le debía 20.000 mrs.; el carpintero Juan López, v. de Cádiz, 5.000 mrs. y el carpintero Antonio Gómez, su cuñado, 1.000 mrs., de resto de los 5.000 mrs. que Gómez había recibido de Juan Ortiz. Mandó que lo enterrasen en San Andrés, en la sepultura que allí tenía. Dejó a sus hermanas Guiomar Núñez e Inés de Ávila 1.000 y 2.000 mrs. respectivamente; a Isabel Martínez (su hermana o prima) 1.000 mrs., a Beatriz Fernández (San Andrés) 8.000 mrs. en recompensa de sus desvelos y a Inés de Pernía cuatro reales. Nombró heredera a su madre. Dejó por albaceas a Antonio Gómez, su cuñado, a Álvaro Marmolejo y a Andrés de Barrasa (4.1502, f. 19v).

240. Luis Gudínez, v. de Bailén. ¿15?-11-01: contrata a Cristóbal de Borja. Se avecindó en el Bonao (R-D 201).

241. Luis Monte, n. de Segovia, criado de la condesa de Camiña (escrito "Camiño"), mayor de 22 años y menor de 25. 25-9-01: compra mercaderías al mercader Fernando de León (cf. Alonso Gutiérrez de Villanueva).

242. Luis Moyano, v. de Córdoba. 9-12-01: compra vino a Luis de Arriaga y a Pedro de Salzedo.

243. Luis de Quesada, criado del doctor Juan de Vique (Santa María la Blanca). 23-11-01: contrata a Francisco. Se avecindó en Santo Domingo (R-D 173).

244. Marcial de Movellán, lavador de oro, n. de la Montaña. 15-10-01: con el bonetero Francisco Jiménez (Santa María). Año y medio. 5/8 partes de las ganancias (3.1501, f. 811v). 11-11-01: debe a Juan de Mojados 1.470 mrs.: 860 de préstamo (que van a riesgo de Mojados en el navío Santa Ana (maestre: Juan Martín de Asejo, v. de Palos) y el resto en mercaderías (que van a riesgo de Mojados en el mismo Santa Ana): a pagar en la Española en un plazo de 15 días (3.1501, f. 895r). Se avecindó en Santo Domingo (R-D 159).

245. Martín de Artiaga, escudero, v. de Medina del Campo. 1-12-01: contrata a Cristóbal de la Fuente.

246. Martín Domínguez, n. de Aracena, h. de Juan Gómez (m.). 14-10-01: con Álvaro Bravo (San Isidoro). 2 años y medio. 4.000 mrs. más el $10 \%$ (3.1501, f. 806r).

247. Martín de Gamboa, criado de don Enrique Enríquez, mayordomo mayor del rey. 23-12-01: de mancomún con el escribano Juan Álvarez de Alcalá debe 9.000 mrs. a Juan de la Palma, v. de Trigueros, por mercadería que va cargada en la nao Santa María (maestre: Sebastián de Urtieta, v. de San Sebastián): a pagar en Santo Domingo (5.1501, f. 278r). Volvió a la Península con Juan de Ayala, Miguel Díaz, Gómez de Ribera y Antonio Maldonado, consiguiendo que se les concediera el 28 de julio de 1503 licen- 
cia para cargar y llevar las cosas que pudiesen necesitar los vs. de Santo Domingo y para fletar a este fin las naves que fuesen menester (AGI Indif. 418, I f. 113r). En 1514 seguía avecindado en Santo Domingo (R-D 137).

248. Martín González de Cabra, h. de Antón González (m., v. que fue de Écija). 19-10-01: con Juan Álvarez de Gijón, v. de Valladolid. 3 años. 5.000 mrs. (3.1501, f. 824r).

249. Martín Martínez, presbítero, beneficiado y v. de Castromocho (Palencia). 8-11-01: contrata a Alonso de Espinosa, Juan de Zamora y Francisco García. 10-11-01: contrata a Fernando de Almazán.

250. Martín de Salinas (mayor de 23 años y menor de 25), n. de Salinas de Añana. 20-11-01: con Juan de Saravia (San Isidoro) y Fernando de Lugo, v. de Sanlúcar de Barrameda. 2 años. 6.000 mrs. más el $10 \%$ del oro $(5.1501$, f. $218 \mathrm{v})$.

251. Mateo, n. de Piedrahita. 11-11-01: con Gonzalo de Ocampo, v. de Cáceres. 3 años. 3.000 mrs. más el $10 \%$ (3.1501, f. 893v).

252. Miguel Esteban (mayor de 22 años y menor de 25), n. de Zamora. 29-10-01: con Juan Barba, h. del veinticuatro Juan Barba. 2 años. 6.000 mrs. el primer año y 10.000 el segundo $(3.1501$, f. $860 v)$.

253. Miguel de Sigüenza, h. de Juan de Marigómez, v. de Sigüenza. 11-12-01: con Fernando de Robles (San Marcos). 2 años. 3.600 mrs. más la octava parte $(5.1501$, f. $259 \mathrm{v})$.

254. Pedro (20 años), h. de Pedro de Perea, n. de Perea en la Montaña. 21-10-01: con Bernardino de Sauzedo, v. de Guadalajara. 2 años. 8.000 mrs. (15.1501, f. 621r).

255. Pedro (21 años), de color negro, criado que fue del mercader genovés Jácome de Sorvanis. 16-10-01: con Juan de Saravia. 2 años. 6.000 mrs. más el $10 \%$ (15.1501, f. 604r).

256. Pedro Asturiano, h. de Alonso de los Llanos, v. de Llanes (concejo de Parres, en el principado de Asturias). 11-12-01: con Pedro de Barrera (Salvador). Por todo el tiempo que estuviere Pedro de Barrera en la Española. $3.600 \mathrm{mrs}$. más la octava parte (5.1501, f. 259r).

257. Pedro de ***, v. de Villanueva de la Serena. 9-12-01: debe a Luis de Arriaga y a Pedro de Salzedo 1.810 mrs. de una bota de vino (15.1501, f. 771r).

258. Pedro de Aragón, trabajador, v. de Granada. 19-11-01: con Sebastián de Guevara, v. de Lorca. 5 años. La quinta parte (15.1501, f. 752r).

259. Pedro de Asturias, n. de *** (Asturias de Oviedo), con Juan de Esquivel. *** años. 8.000 mrs. (4.1502, cuadernillo aparte, sin fecha).

260. Pedro de Ávila, trabajador (Santa María). 9-12-01: debe a Luis de Arriaga y a Pedro de Salzedo 1.810 mrs. de una bota de vino (15.1501, f. 769r).

261. Pedro de Barrera, h. de Rodrigo de la Barrera (Salvador). 11-12-01: contrata a Benito de Villarreal y a Pedro de Asturias. 


\section{LA GENTE DE OVANDO EN LOS PROTOCOLOS HISPALENSES}

262. Pedro Bonifaz, v. de Sevilla. 9-12-01: debe a Luis de Arriaga y a Pedro de Salzedo 1.810 mrs. de una bota de vino (15.1501, f. 771r).

263. Pedro de Bruxeles (Triana). 9-12-01: debe a Luis de Arriaga y a Pedro de Salzedo $2.320 \mathrm{mrs}$. de una bota de vino (15.1501, f. 771r).

264. Pedro de Busto, zapatero, n. de Briviesca. 17-11-01: con Fernando de Lugo, v. de Sanlúcar de Barrameda. 2 años. 6.000 mrs. más el $10 \%$ (5.1501, f. 210r).

265. Pedro Cabelo, cordonero, marido de Ana Martín (Santa María). 10-12-01: con Álvaro Bravo (Sevilla), por *** años y medio. 5.000 mrs. (3.1501, f. 960v).

266. Pedro Díaz de las Cuevas (23 años), v. de Mancilla (¿Mansilla de las Mulas?). 4-11-01: con Francisco de Soreta, v. de Alcalá de Henares. 5 años. 7.000 mrs. (15.1501, f. 672v).

267. Pedro Fernández (mayor de 20 años y menor de 25), peraile, marido de Marina Rodríguez (Santa María). 7-10-01: con el albañil Francisco de Salas. 2 años. 8.000 mrs. (3.1501, f. 784v).

268. Pedro Gómez. 7-10-91: con el físico Diego Ponce. Durante todo el tiempo que el doctor estuviese en la Española. A medias (3.1501, f. 784r).

269. Pedro de Herrera (mayor de 18 años y menor de 25), h. de Luis de Herrera (m.), n. de Medina del Campo. 23-12-01: con Alonso Núñez de Toledo (Santa Cruz). 2 años. 6.000 mrs. más el $10 \%$ (5.1501, f. 279r). Se avecindó en Santiago (R-D 113).

270. Pedro Jiménez de Utrera, trabajador, v. de Utrera. 4-12-01: con Juan de Mojados. 3 años. 8.000 mrs. (3.1501, f. 949r).

271. Pedro de Madrid, curtidor. 17-11-01: con los curtidores Alonso de Alba, Pedro de Madrid y Diego de Madrid debe 8.000 mrs. a Juan Sánchez de la Tesorería (Santa María).

272. Pedro de Madrigal (menor de 20 años), h. de Alonso de Cabezas, v. de Madrigal. 7-12-01: con Carlos de Hontiveros. 3 años. 8.000 mrs. (15.1501, v. 760v).

273. Pedro Martín, trabajador, h. de Martín de Morón (m.). 9-12-01: con Gonzalo de Ocampo, v. de Cáceres. 3 años. 4.000 mrs. más el $10 \%$ (3.1501, f. 963r).

274. Pedro Martín, trabajador, v. de Ayllón. 7-12-01: con Atanasio Pedro Díaz de la Costana, v. de Azuaga. 3 años. 20 ducados más el $10 \%$ (15.1501, f.761r).

275. Pedro Martín, trabajador, v. de El Espinal (Segovia). 11-11-01: con Frutos de Deleitosa. 4 años. 8.000 mrs. (15.1501, f. 713v). Se avecindó en Lares de Guahaba (R-D 214).

276. Pedro del Rebollar, n. del valle de Carriedo (marquesado de Santillana), del lugar del Azenillo. 22-9-01: con Juan de Villa y Juan de Salamanca. 2 años. 3.000 mrs. más el $10 \%$ (4.1501, f. 175v).

277. Pedro Romero, trabajador, h. de Alonso García Romero, v. de Torredonjimeno. 23-11-01: con Diego de Nicuesa. 2 años. 8.000 mrs. (5.1501, 
f. 226r). Se avecindó en La Sabana (R-D 235). Testificó en 1517 en el juicio de residencia que hizo Zuazo a los jueces de apelación de la Española (AGI Just. 42, f. 53ss.).

278. Pedro de Salzedo. 9-12-01: de mancomún con Luis de Arriaga vende vino a Juan Álvarez de Gijón, Juan de Molina-Gonzalo Suárez, Diego de Nicuesa, Carlos de Hontiveros, Gonzalo de Ocampo, Juan de Molina, Diego Ramírez Hortelano-Juan de Madrid, Juan de Madrid, Antón ***, Lope de Leiva, García de Buitrago, Pedro de Ávila, Juan Gutierre, Jerónimo de Valenzuela, Juan Gil, Alonso Tejeiro, Diego Ruiz de la Muela, Gutierre Bezerra, Gil Delgado, Álvar Pérez de ¿Incuestes?, Rodrigo Mexía, Diego ***, Pedro Bonifaz, Juan de Monleón, Pedro Sánchez Villar, Jerónimo de Herrera, Luis Moyano, Diego Ortiz-Alonso de Pallares, Antonio de Aguilar, Sancho de Santisteban, Pedro de ***, Esteban de Molina, Pedro de Bruxeles, Francisco de To***, Cristóbal de los Ríos y Juan García de Cebreros. Avecindado en Santo Domingo (R-D 156), firmó a fines de 1517 un memorial dirigido al rey con otros vs. de la ciudad (G-F II, 133).

279. Pedro Sánchez Villar, v. de Baeza. 9-12-01: debe a Luis de Arriaga y a Pedro de Salzedo $3.620 \mathrm{mrs}$. de dos botas de vino (15.1501, f. 771r).

280. Pedro de Sanlúcar, h. de Gonzalo González (m.), v. de Sanlúcar la Mayor (Santa María). 10-1-02: debe a Francisco de Pomareda cinco ducados que éste le presta para llevarlo consigo a la Española y darle pasaje y manutención: a pagar en dicha isla en un plazo de 20 días $(4.1502$, f. 49r).

281. Pedro de Torres, h. de Francisco de Torres, v. de Buitrago. 3-11-01: con Carlos de Hontiveros. 2 años. 7.000 mrs. (15.1501, f. 671v). Se avecindó en Santo Domingo (R-D 151).

282. Pedro de Utrera (mayor de 18 años). 9-12-01: con Gonzalo de Ocampo, v. de Cáceres. 3 años. *** (3.1501, f. 963r).

283. Rodrigo de Alburquerque, v. de Salamanca. 18-11-01: de mancomún con Juan de Berlanga, v. de Burgo de Osma, debe 3.200 mrs. al herrero Juan de Monleón (San Juan) por 300 herramientas que le habían comprado para llevar a Indias: a pagar en Santo Domingo en un plazo de 30 días (9.1501). Fue como alcaide (CCD III, 1418). Se avecindó de La Concepción (GFO IV 2 [BAE 117, 95 a]). En 1514 hizo un nuevo repartimiento de indios.

284. Rodrigo de Grivalda. 25-10-01: contrata a Antón Bravo.

285. Rodrigo de Lepe, sillero (Santa María). 4-9-01: contrata a Juan Pérez Valenciano y a Francisco frutero.

286. Rodrigo Mexía, v. de Córdoba. 9-12-01: debe a Luis de Arriaga y a Pedro de Salzedo 4.120 mrs. de dos botas de vino (15.1501, f. 770v). Ha de ser el futuro capitán y fundador de Puerto Real y Lares de Guahaba (BC II 10 [BAE 96, 31 a, 32 a]; GFO III 12 [BAE 117, 83 a]). El 22 de julio de 1504 Rodrigo Mexía, capitán de La Trinidad (maestre: Juan Bermúdez), y 


\section{LA GENTE DE OVANDO EN LOS PROTOCOLOS HISPALENSES}

Rodrigo de Cuéllar, capitán del San Cristóbal (maestre: Nortes), entregaron en la Casa de la Contratación 40.000 pesos y dos granos, que pesaron 39.915 pesos, siete tomines y nueve granos (AGI Contrat. 4674, f. 36v).

287. Ruy Páez de Sotomayor, v. de Jaén. 26-11-01: contrata a Juan Rodríguez.

288. Sancho de Santisteban, v. de Arévalo. 9-12-01: debe a Luis de Arriaga y a Pedro de Salzedo 2.310 mrs. de una bota de vino (15.1501, f. 771v).

289. Sebastián de Guevara, v. de Lorca. Contrata a Bartolomé de Valverde (26-10-01) y a Pedro de Aragón (19-11-01). Se avecindó en Santo Domingo (R-D 101).

290. Sebastián de Llara (¿Llerena?). 10-11-01: recibe poder del trapero Diego de Chillas (Santa Cruz) para cobrar las deudas que se le debían a Chillas en la Española (5.1501, f. 257v).

291. Sebastián de Valencia, v. de Valencia. Contrata a Juan de Medina (22-11-01). Se avecindó en La Buenaventura (R-D 194).

292. Simón Bermejo, v. de La Rambla. 10-11-01: con Carlos de Hontiveros. 3 años. 10.000 mrs. (15.1501, f. 712r).

293. Simón López, h. de Bartolomé Sánchez, v. de La Rambla. 10-11-01: con Carlos de Hontiveros. 3 años. 10.000 mrs. (15.1501, f. 712r).

\section{PASAJEROS DE NOMBRE ILEGIBLE}

294. *** (¿Pedro de Montesdoca?), trabajador, marido de María *** (¿Jiménez?), v. del Casar de Cáceres. 9-12-01: con Gonzalo de Ocampo, v. de Cáceres. 3 años. 5.000 mrs. más el $10 \%$ (3.1501, f. 962r).

295. *** de Vargas, correero, marido de Catalina de Morales (San Martín). 6-1-02: hizo testamento antes de partir a las Indias. Debía a su compadre el clérigo Juan de Quadros siete ducados. Dispuso que lo sepultasen en la catedral de Sevilla. Encomendó a su mujer el patronazgo de la capellanía que había instituido en San Andrés su suegra, Beatriz Fernández. Dejó por herederos a sus hijos Pedro, Beatriz, Leonor, Alonso y Estebania. Nombró albaceas a Quadros y a su hermana Leonor de Vargas (4.1502, f. 32r). ¿El Rodrigo de Vargas avecindado en el Bonao (R-D 200) y testigo en el juicio de residencia que en 1517 hizo Zuazo a los jueces de apelación de la Española (AGI Just. 42, f. 201v)?

296. *** Lozano, merchante de bestias, v. de Jerez de la Frontera, debe a Álvaro de Reinoso $3.500 \mathrm{mrs}$. por mercaderías que van cargadas en la carabela de Quincoces: a pagar en la Española en un plazo de 30 días a Juan Velázquez, criado de *** (parece que diría "Sus Altezas"). Asegura el pago con 50 puercos que tiene arrendados a Pedro Sanchez Malillo, v. de Jerez (4.1502, cuadernillo aparte, sin fecha). 
297. ***, h. de Fernando de Ma*** (mayor de 20 años y menor de 25), n. de Belorado. 9-12-01: con Gómez de Alfaro (Sevilla). 3 años. 4.000 mrs. (3.1501, f. 960r).

\section{MAESTRES}

Ovando partió con treinta y dos naves. Las escrituras notariales permiten registrar negocios de los siguientes maestres de la armada:

1. Alonso Venegas, v. de Palos, maestre de la carabela Santa Ana, surta en el río de Saltés. 30-11-01. debe a Alonso Fernández de Bolaños, regidor de Gibraleón, 1.500 mrs. por tres puercos que lleva en su carabela a la Española a riesgo y ventura de Bolaños: a pagar en la Española en un plazo de 15 días $(3.1501$, f. $939 \mathrm{v})$.

2. Andrés García Cansino, v. de Palos, maestre de la carabela Santa Cruz. Llevó mercancías de Diego Marque.

3. Bartolomé Colín, v. de Palos, maestre de la carabela Colina. Llevó mercancías de Frutos de Deleitosa.

4. Cristóbal Enríquez, v. de Palos, maestre de la carabela La Bachillera. Llevó mercancías de Cristóbal de Palacios. "Esteban" lo llama el P. Ortega (CDD III, 1422), pero la lectura del documento es muy nítida; podría ser error del escribano, confundido por el otro "Cristóbal".

5. Diego Rodríguez, cómitre (Triana), maestre de la carabela Santa Catalina. 5-11-01: debe a Ruy Gonzalez de la Sal 16.000 mrs. de préstamo para "forneçer" su carabela que iba a las Indias $(15.1501$, f. $678 \mathrm{v})$. 17-1-02: debe a Luis Guerra (Triana) 22.000 mrs. que le prestó para el despacho de su carabela, que van a riesgo de Guerra: a pagar en la Española en un plazo de ocho días (4.1502, f.114v). No figura en la lista de $C D D$ III, 1421-22.

6. Diego Rodríguez (Triana), maestre de El Espíritu Santo. Llevó mercancías de Juan de Tajuste. No figura en la lista de CDD III, 1421-22.

7. Fernán Pérez Mateos, v. de Palos, maestre de la carabela Santa María de la Rábida. Llevó mercancías de Cristóbal Barrera, v. de Trigueros.

8. Francisco García, v. de Palos, maestre de la carabela La Garza ("Lagarta" transcribe mal el padre Ortega [CDD III, 1422]): debe a Alonso Fernández de Bolaños, v. de Gibraleón, 4.000 mrs. de ocho puercos que le había comprado, a $500 \mathrm{mrs}$. el puerco, que van a riesgo de Gibraleón: a pagar en Sevilla (5.1501, f. 240v). Llevó mercancías de Francisco de Hoz. La Garza dio nombre a la isla también llamada Bermuda (GFO II 9 [BAE 117, 38]).

9. Francisco Quintero, v. de Palos. Cf. Francisco de Valdés. No figura en la lista de $C D D$ III, 1421-22. 


\section{LA GENTE DE OVANDO EN LOS PROTOCOLOS HISPALENSES}

10. Gonzalo Rodríguez (San Vicente), maestre de la carabela Santa Catalina. 8-11-01: presta 6.400 mrs. a Juan y Fernando de Arce. No figura en la lista de $C D D$ III, 1421-22.

11. Juan Martín de Asejo, v. de Palos, maestre de la carabela Santa Ana. Llevó a las Indias a los curtidores Alonso de Alba y Pedro de Madrid, así como transportó mercancías de Marcial de Movellán.

12. Juan Monje, v. de Palos, maestre de la carabela La Monja. Llevó mercancías de Cristóbal de Palacios, de Juan García y de Juan Marquesín.

13. Juan de Peñafiel (Triana), maestre de la nao Santo Domingo. debe a Juan Bastidas (San Vicente) 5.780 mrs. de préstamo para el despacho de su carabela, que van a riesgo de Bastidas: a pagar en Santo Domingo en un plazo de ocho días (4.1502, f. 56r). 10-1-02: debe a Luis Guerra (Triana) 7.000 mrs. que le prestó para el despacho de su carabela, que van a riesgo de Guerra: a pagar en la Española en un plazo de diez días (4.1502, f. 50v). Peñafiel otorga deber a Pedro Fernández del Alcoba 3.376 mrs. por un contrato parecido $(4.1502$, f. 50v). Llevó mercancías de Alonso Fernández Melgarejo, Diego de Escobar y Juan de Molina. No figura en la lista de CDD III, 1421-22.

14. ¿Juan Quintero Príncipe, marinero, v. de Palos? 13-12-01: contrata a Alonso de Mayorga. No figura en la lista de CDD III, 1421-22.

15. Martín Domingo, v. de Palos, maestre de la carabela ***. Luis de Arriaga contribuyó a su despacho. No figura en la lista de CDD III, 1421-22.

16. Martín Fernández Pacho, maestre de la carabela San Andrés, marido de Isabel de Medina (San Andrés). 7-1-02: recibe poder de María Fernández para cobrar las deudas de su hijo Juan agujetero, muerto en Indias. 3-1-02: presta 8.000 mrs. a Alonso Fernández de Castilla (Omnium sanctorum). 9-12-01: presta a Diego de Nicuesa 26.000 mrs. de mercancía. 6-1-02: hace testamento antes de partir a las Indias. Dispuso que le diesen sepultura en San Andrés. Dejó por herederos a sus hijos María Álvarez y Juan de Medina. Nombró albaceas a Juan de Medina y a su mujer (4.1502, f. 33r). 7-1-02: recibe poder de María Fernández para cobrar las deudas de su hijo Juan agujetero, muerto en Indias. Llevó mercaderías de Diego de Nicuesa. No figura en la lista de CDD III, 1421-22.

17. Sebastián de Urtieta, v. de San Sebastián, maestre de la nao Santa María. Llevó mercancía de Martín de Gamboa. No figura en la lista de CDD III, 1421-22.

Recibido el 8 de diciembre de 2005 Aceptado el 17 de marzo de 2006 